\title{
Monetary policy, inflation and unemployment In defense of the Federal Reserve
}

\author{
Nicolas Groshenny*
}

July 2010

\begin{abstract}
To what extent have monetary policy shocks been helpful at stabilizing inflation and unemployment? To address this question, I employ Bayesian techniques and post-1984 U.S. data to estimate a medium-scale DSGE model with labor market frictions. I use the estimated model to back out the time series of the shocks that have hit the U.S. economy over the period 1985:Q1 - 2009:Q4 as well as the path of the natural rate of unemployment. Historical decompositions of the model-consistent unemployment gap emphasize the expansionary effects of monetary policy shocks during each of the three recessions embedded in the sample period. In counterfactual experiments where the estimated monetary policy disturbances are turned off, the unemployment gap becomes significantly more volatile and the U.S. economy enters deflation in 2002 and again in 2008. These results therefore suggest that the non-systematic component of monetary policy contributed materially to enhancing macroeconomic stability during the last decade.
\end{abstract}

Keywords: DSGE models, business cycles, unemployment gap, monetary policy JEL codes: E32, C51, C52

*Reserve Bank of New Zealand, Economics department. email: nicolas.groshenny@rbnz.govt.nz. I am especially grateful to Ulf Söderström for very helpful comments. I thank Larry Christiano, Iris Claus, Manu De Veirman, Michael Dotsey, Francesco Furlanetto, Mark Gertler, Leni Hunter, Punnoose Jacob, Günes Kamber, Leo Krippner, Thomas Lubik, Anella Munro, Pierre-Daniel Sarte, Christie Smith and an anonymous referee for useful suggestions. I am grateful to participants at the following conferences: RBNZ-CIED Monetary Policy Conference, Wellington December 2009, ISCEF, Sousse February 2010, SWIM, Auckland March 2010, AMW, Wellington April 2010. 


\section{Introduction}

The Federal Reserve sets the short-term nominal interest rate in order to achieve its dual goals of price stability and and maximum sustainable employment. Recently, a debate has emerged regarding the justification of the actions of the Federal Reserve in the post-1984 era. Some economists such as Taylor (2007) criticize the Federal Reserve's conduct of monetary policy during the 2000s, arguing that the policy instrument rate was kept too low during the recovery following the 2001 recession. In contrast, Bernanke (2010) and Svensson (2009) among others argue that the historical path of the federal funds rate was helpful in reducing the risk of deflation. ${ }^{1}$ This paper asks whether monetary policy shocks have been helpful in stabilizing inflation and the unemployment gap during the post 1984 era?

I build a New Keynesian model with search and matching frictions in the labor market. ${ }^{2}$ The model incorporates the standard features introduced by Christiano, Eichenbaum and Evans (2005) and Smets and Wouters (2007) that help fitting the data. I use post-1984 quarterly US data on seven key aggregate variables to estimate the model with Bayesian techniques. I then use the estimated model to back out the path of the natural rate of unemployment and to construct a model-consistent measure of the unemployment gap. Following Sala, Söderström and Trigari (2008), the natural rate of unemployment is defined as the unemployment rate consistent with flexible prices and wages in absence of price-markup shocks and bargaining-power shocks. Given the dual goals officially pursued by the Federal Reserve, the unemployment gap is an important concept for American monetary policy makers. Hence, the estimates of the unemployment gap will be a crucial for assessing the practice of monetary policy. The historical decomposition of the unemployment gap reveals the expansionary effects of monetary policy disturbances during the three recessions embedded in the period 1985:Q1-2009:Q4. In a counterfactual experiment where the estimated historical monetary policy shocks are turned off, the U.S. economy enters deflation in 2002 and again in 2008. Moreover the unemployment gap becomes significantly more volatile. The paper's main result therefore suggests that unanticipated deviations from the Federal reserve interest rate rule did contribute to stabilizing the macroeconomy over the last decade.

The rest of the paper proceeds as follows: Section 2 describes the model. Section 3 explains the econometric strategy. Section 4 presents estimates of the natural rate of unemployment, assesses the performance of the Federal Reserve in stabilizing inflation and unemployment and examines the role of monetary policy shocks. Section 5 conducts sensitivity analysis. Section 6 concludes.

\footnotetext{
${ }^{1}$ Dokko, Doyle, Kiley, Kim, Sherlund, Sim and van den Heuvel (2009) find a limited role for monetary policy in the housing bubble.

${ }^{2}$ See for example Trigari (2009), Walsh (2005), Krause and Lubik (2007), Sveen and Weinke (2008), Gertler, Sala and Trigari (2008) and Groshenny (2009).
} 


\section{Model}

The model combines the medium-scale model in Christiano et al. (2005) with the labor-search model due to Diamond, Mortensen and Pissarides. ${ }^{3}$ The economy consists of a representative family, a representative finished goods-producing firm, a continuum of intermediate goodsproducing firms indexed by $i \in[0,1]$, a central bank and a government that sets monetary and fiscal policy respectively. Firms adjust labor exclusively through job creation and face convex hiring costs as in Yashiv (2006). This feature helps the model to capture the observed high persistence in vacancies and unemployment. Fluctuations are driven by seven disturbances: a neutral technology shock, an investment-specific technology shock, a risk-premium shock, a price-markup shock, a bargaining-power shock, an exogenous spending shock and a monetary policy shock.

Gertler et al. (2008) (henceforth GST) have shown that this kind of model fits the data as well as the benchmark model without unemployment exemplified by Smets and Wouters (2007). Moreover, there are three related advantages in introducing equilibrium search unemployment into the standard toolbox for monetary policy analysis: First, this theoretical framework generates predictions about the unemployment rate and other labor market variables such as the vacancy rate. Second, in this framework, sticky wages are not subject to the Barro critique. ${ }^{4}$ This is important because Christiano et al. (2005) and Smets and Wouters (2007) provide evidence suggesting that wage stickiness is a more important ingredient than price stickiness in accounting for the persistence observed in the data. Third, Hall (1997) and Chari, McGrattan and Kehoe (2007) have stressed the importance of variations in the labor wedge, i.e. the gap between the marginal product of labor and the marginal rate of substitution between leisure and consumption, to account for business cycle fluctuations. ${ }^{5}$ Introducing search and matching frictions into the equilibrium business cycle model and using labor market variables in the estimation contribute to endogenising and identifiying the labor wedge.

The model follows the model in GST quite closely except for a few deviations. First, GST features a preference shock to the representative household's discount factor. Instead, my model features a risk-premium shock as in Smets and Wouters (2007). Second, GST use sticky prices à la Calvo while I opt for quadratic price adjustment costs à la Rotemberg. Third, I introduce nominal wage stickiness as in Arsenau and Chugh (2008) by assuming that firms bear the costs of adjusting nominal wage. Finally, the econometric strategies are also somewhat different. GST use data on total hours worked whereas I use data on the vacancy/unemployment ratio. Finally, their sample period goes from 1960:Q1 to 2005:Q1. Instead my sample starts in 1985:Q1 after the Great Moderation and the Volcker's disinflation.

The representative household There is a continuum of identical households of mass one. Each household is a large family, made of a continuum of individuals of measure one.

\footnotetext{
${ }^{3}$ See Pissarides (2000)

${ }^{4}$ Barro (1977) argues that wages may not have allocational effects for the existing firm-worker pairs due to the long-run nature of workers and firms relationships.

${ }^{5}$ See also Sala, Söderström and Trigari (2010).
} 
Family members are either working or searching for a job. ${ }^{6}$ Following Merz (1995), I assume that family members pool their income before the head of the family chooses optimally per capita consumption.

The representative family enters each period $t=0,1,2, \ldots$, with $B_{t-1}$ bonds and $\bar{K}_{t-1}$ units of physical capital. At the beginning of each period, bonds mature, providing $B_{t-1}$ units of money. The representative family uses some of this money to purchase $B_{t}$ new bonds at nominal cost $B_{t} / r_{t}^{B}$, where $r_{t}^{B}$ denotes the gross nominal interest rate between period $t$ and $t+1$.

The representative household owns capital and chooses the capital utilization rate, $u_{t}$, which transforms physical capital into effective capital according to

$$
K_{t}=u_{t} \bar{K}_{t-1}
$$

The household rents $K_{t}(i)$ units of effective capital to intermediate-goods-producing firm $i \in$ $[0,1]$ at the nominal rate $r_{t}^{K}$. The household's choice of $K_{t}(i)$ must satisfy

$$
K_{t}=\int_{0}^{1} K_{t}(i) d i .
$$

The cost of capital utilization is $a\left(u_{t}\right)$ per unit of physical capital. I assume the following functional form for the function $a$,

$$
a\left(u_{t}\right)=\phi_{u 1}\left(u_{t}-1\right)+\frac{\phi_{u 2}}{2}\left(u_{t}-1\right)^{2}
$$

and that $u_{t}=1$ in steady state.

Each period, $N_{t}(i)$ family members are employed at intermediate goods-producing firm $i$ $\in[0,1]$. Each worker employed at firm $i$ works a fixed amount of hours and earns the nominal wage $W_{t}(i) . N_{t}$ denotes aggregate employment in period $t$ and is given by

$$
N_{t}=\int_{0}^{1} N_{t}(i) d i
$$

The remaining $\left(1-N_{t}\right)$ family members are unemployed and and each receives nominal unemployment benefits $b_{t}$, financed through lump-sum taxes.

During period $t$, the representative household receives total nominal factor payments $r_{t}^{K} K_{t}+$ $W_{t} N_{t}+\left(1-N_{t}\right) b_{t}$. In addition, the household also receives nominal profits $D_{t}(i)$ from each firm $i \in[0,1]$, for a total of

$$
D_{t}=\int_{0}^{1} D_{t}(i) d i .
$$

In each period $t=0,1,2, \ldots$, the family uses these resources to purchase finished goods, for both consumption and investment purposes, from the representative finished goods-producing firm at

\footnotetext{
${ }^{6}$ The model abstracts from the labor force participation decision.
} 
the nominal price $P_{t}$. The law of motion of physical capital is

$$
\bar{K}_{t} \leq(1-\delta) \bar{K}_{t-1}+\mu_{t}\left[1-S\left(\frac{I_{t}}{I_{t-1}}\right)\right] I_{t},
$$

where $\delta$ denotes the depreciation rate. The function $S$ captures the presence of adjustment costs in investment, as in Christiano et al. (2005). I assume the following functional form for the function $S$,

$$
S\left(\frac{I_{t}}{I_{t-1}}\right)=\frac{\phi_{I}}{2}\left(\frac{I_{t}}{I_{t-1}}-g_{I}\right)^{2},
$$

where $g_{I}$ is the steady-state growth rate of investment. Hence, along the balanced growth path, $S\left(g_{I}\right)=S^{\prime}\left(g_{I}\right)=0$ and $S^{\prime \prime}\left(g_{I}\right)=\phi_{I}>0 . \mu_{t}$ is an investment-specific technology shock affecting the efficiency with which consumption goods are transformed into capital. The investmentspecific shock follows the exogenous stationary autoregressive process

$$
\ln \left(\mu_{t}\right)=\rho_{\mu} \ln \left(\mu_{t-1}\right)+\varepsilon_{\mu t},
$$

where $\varepsilon_{\mu t}$ is i.i.d.N $\left(0, \sigma_{\mu}^{2}\right)$.

The family's budget constraint is given by

$$
\begin{aligned}
P_{t} C_{t}+P_{t} I_{t}+\frac{B_{t}}{\epsilon_{b t} r_{t}^{B}} \leq & B_{t-1}+W_{t} N_{t}+\left(1-N_{t}\right) b_{t}+r_{t}^{K} u_{t} \bar{K}_{t-1} \\
& -P_{t} a\left(u_{t}\right) \bar{K}_{t-1}-T_{t}+D_{t}
\end{aligned}
$$

for all $t=0,1,2, \ldots$ Let $\Lambda_{t}$ denote the Lagrange multiplier on the family's budget constraint (9).

As in Smets and Wouters (2007), the shock $\epsilon_{b t}$ drives a wedge between the central bank's instrument rate $r_{t}^{B}$ and the return on assets held by the representative family. As noted by De Graeve, Emiris and Wouters (2009), this disturbance works as an aggregate demand shock and generates a positive comovement between consumption and investment. The risk-premium shock $\epsilon_{b t}$ follows the autoregressive process

$$
\ln \epsilon_{b t}=\rho_{b} \ln \epsilon_{b t-1}+\varepsilon_{b t},
$$

where $0<\rho_{b}<1$, and $\varepsilon_{b t}$ is i.i.d. $N\left(0, \sigma_{b}^{2}\right)$.

The family's lifetime utility is described by

$$
E_{t} \sum_{s=0}^{\infty} \beta^{s} \ln \left(C_{t+s}-h C_{t+s-1}\right)
$$

where $0<\beta<1$. When $h>0$, the model allows for habit formation in consumption and consumption responds gradually to shocks.

The head of the family chooses $C_{t}, B_{t}, u_{t}, I_{t}$, and $\bar{K}_{t}$ for each $t=0,1,2, \ldots$ to maximize the expected lifetime utility (11) subject to the constraints (6) and (9). 
The representative finished goods-producing firm During each period $t=0,1,2, \ldots$, the representative finished goods-producing firm uses $Y_{t}(i)$ units of each intermediate good $i \in[0,1]$, purchased at the nominal price $P_{t}(i)$, to manufacture $Y_{t}$ units of the finished good according to the constant-returns-to-scale technology described by

$$
\left[\int_{0}^{1} Y_{t}(i)^{\left(\theta_{t}-1\right) / \theta_{t}} d i\right]^{\theta_{t} /\left(\theta_{t}-1\right)} \geq Y_{t}
$$

where $\theta_{t}$ translates into a random shock to the markup of price over marginal cost. This markup shock follows the autoregressive process

$$
\ln \left(\theta_{t}\right)=\left(1-\rho_{\theta}\right) \ln (\theta)+\rho_{\theta} \ln \left(\theta_{t-1}\right)+\varepsilon_{\theta t},
$$

where $0<\rho_{\theta}<1, \theta>1$, and $\varepsilon_{\theta t}$ is i.i.d.N $\left(0, \sigma_{\theta}^{2}\right)$.

Intermediate good $i$ sells at the nominal price $P_{t}(i)$, while the finished good sells at the nominal price $P_{t}$. Given these prices, the finished goods-producing firm chooses $Y_{t}$ and $Y_{t}(i)$ for all $i \in[0,1]$ to maximize its profits

$$
P_{t} Y_{t}-\int_{0}^{1} P_{t}(i) Y_{t}(i) d i,
$$

subject to the constraint (12) for each $t=0,1,2, \ldots$. The first-order conditions for this problem are (12) with equality and

$$
Y_{t}(i)=\left[\frac{P_{t}(i)}{P_{t}}\right]^{-\theta_{t}} Y_{t}
$$

for all $i \in[0,1]$ and $t=0,1,2, \ldots$.

Competition in the market for the finished good drives the finished goods-producing firm's profits to zero in equilibrium. This zero-profit condition determines $P_{t}$ as

$$
P_{t}=\left[\int_{0}^{1} P_{t}(i)^{1-\theta_{t}} d i\right]^{1 /\left(1-\theta_{t}\right)}
$$

for all $t=0,1,2, \ldots$

The representative intermediate goods-producing firm Each intermediate goodsproducing firm $i \in[0,1]$ enters in period $t$ with a stock of $N_{t-1}(i)$ employees carried from the previous period. At the beginning of period $t$, before production starts, $\rho N_{t-1}(i)$ olds jobs are destroyed, where $\rho$ is the job destruction rate. ${ }^{7}$ The pool of workers $\rho N_{t-1}$ who have lost their job at the beginning of period $t$ start searching immediately and can possibly be hired in period t. $N_{t}(i)$ denotes the pool of employees taking part to production at firm $i$ in period $t$. The law

\footnotetext{
${ }^{7}$ The rate of match dissolution is exogenous. This is consistent with Hall (2005) and Shimer (2005)'s finding that recent business cycle fluctuations in the U.S. labor market mostly come from the job creation margin.
} 
of motion of the stock of productive workers at firm $(i)$ is

$$
N_{t}(i)=(1-\rho) N_{t-1}(i)+m_{t}(i) \text {. }
$$

$m_{t}(i)$ denotes the flow of new employees hired by firm $i$ in period $t$, and is given by

$$
m_{t}(i)=q_{t} V_{t}(i)
$$

where $V_{t}(i)$ denotes vacancies posted by firm $i$ in period $t$ and $q_{t}$ is the aggregate probability of filling a vacancy in period $t$. Workers hired in period $t$ take part to period $t$ production. Employment is therefore an instantaneous margin. However, each period some vacancies and job seekers remain unmatched. As a consequence, a firm-worker pair enjoys a joint surplus that motivates the existence of a long-run relationship between the two parties.

Aggregate employment $N_{t}=\int_{0}^{1} N_{t}(i) d i$ evolves over time according to

$$
N_{t}=(1-\rho) N_{t-1}+m_{t}
$$

where $m_{t}=\int_{0}^{1} m_{t}(i) d i$ denotes aggregate matches in period $t$. Similarly, the aggregate vacancies is equal to $V_{t}=\int_{0}^{1} V_{t}(i) d i$. The pool of job seekers in period $t$, denoted by $S_{t}$, is given by

$$
S_{t}=1-(1-\rho) N_{t-1}
$$

The matching process is described by the following aggregate CRS function

$$
m_{t}=\zeta S_{t}^{\sigma} V_{t}^{1-\sigma}
$$

where $\zeta$ is a scale parameter that captures the efficiency of the matching technology. The probability $q_{t}$ to fill a vacancy in period $t$ is given by

$$
q_{t}=\frac{m_{t}}{V_{t}}
$$

The probability, $s_{t}$, for a job seeker to find a job is

$$
s_{t}=\frac{m_{t}}{S_{t}}
$$

Finally aggregate unemployment is defined by

$$
U_{t} \equiv 1-N_{t}
$$

During each period $t=0,1,2, \ldots$, the representative intermediate goods-producing firm combines $N_{t}(i)$ homogeneous employees with $K_{t}(i)$ units of efficient capital to produce $Y_{t}(i)$ units of intermediate good $i$ according to the constant-returns-to-scale technology described by

$$
Y_{t}(i)=A_{t}^{1-\alpha} K_{t}(i)^{\alpha} N_{t}(i)^{1-\alpha}
$$


$A_{t}$ is an aggregate labor-augmenting technology shock whose growth rate, $z_{t} \equiv A_{t} / A_{t-1}$, follows the exogenous stationary stochastic process

$$
\ln \left(z_{t}\right)=\left(1-\rho_{z}\right) \ln (z)+\rho_{z} \ln \left(z_{t-1}\right)+\varepsilon_{z t},
$$

where $z>1$ denotes the steady-state growth rate of the economy and $\varepsilon_{z t}$ is i.i.d.N $\left(0, \sigma_{z}^{2}\right)$.

Following Yashiv (2006), intermediate goods-producing firms face convex hiring costs, measured in terms of the finished good and given by

$$
\frac{\phi_{N}}{2}\left[\frac{q_{t} V_{t}(i)}{N_{t}(i)}\right]^{2} Y_{t}
$$

where $\phi_{N}$ governs the magnitude of these costs.

Intermediate goods substitute imperfectly for one another in the production function of the representative finished goods-producing firm. Hence, each intermediate goods-producing firm $i \in[0,1]$ sells its output $Y_{t}(i)$ in a monopolistically competitive market, setting $P_{t}(i)$, the price of its own product, with the commitment of satisfying the demand for good $i$ at that price. Firms take the nominal wage as given when maximizing the discounted value of expected future profits.

Each intermediate goods-producing firm faces costs of adjusting its nominal price between periods, measured in terms of the finished good and given by

$$
\frac{\phi_{P}}{2}\left[\frac{P_{t}(i)}{\pi_{t-1}^{\varsigma} \pi^{1-\varsigma} P_{t-1}(i)}-1\right]^{2} Y_{t} .
$$

$\phi_{P}$ governs the magnitude of the price adjustment cost. $\pi_{t}=\frac{P_{t}}{P_{t-1}}$ denotes the gross rate of inflation in period $t . \pi>1$ denotes the steady-state gross rate of inflation and coincides with the central bank's target. The parameter $0 \leq \varsigma \leq 1$ governs the importance of backward-looking behavior in price setting. ${ }^{8}$

Each intermediate goods-producing firm faces quadratic wage-adjustment costs which are proportional to the size of its workforce and measured in terms of the finished good

$$
\frac{\phi_{W}}{2}\left(\frac{W_{t}(i)}{z \pi_{t-1}^{\varrho} \pi^{1-\varrho} W_{t-1}(i)}-1\right)^{2} N_{t}(i) Y_{t},
$$

where $\phi_{W}$ governs the magnitude of the wage adjustment cost. The parameter $0 \leq \varrho \leq 1$ governs the importance of backward-looking behavior in wage setting.

Adjustment costs on the hiring rate, price and wage changes make the intermediate goodsproducing firm's problem dynamic. It chooses $K_{t}(i), N_{t}(i), V_{t}(i)$ and $Y_{t}(i)$ and $P_{t}(i)$ for all $t=0,1,2, \ldots$ to maximize its total market value, given by

$$
E_{t} \sum_{s=0}^{\infty} \beta^{s} \Lambda_{t+s}\left[\frac{D_{t+s}(i)}{P_{t+s}}\right]
$$

\footnotetext{
${ }^{8}$ See Ireland (2007).
} 
where $\beta^{t} \Lambda_{t} / P_{t}$ measures the marginal utility to the representative household of an additional dollar of profits during period $t$ and where

$$
\begin{aligned}
D_{t}(i)= & P_{t}(i) Y_{t}(i)-W_{t}(i) N_{t}(i)-r_{t}^{K} K_{t}(i)-\frac{\phi_{N}}{2}\left(\frac{q_{t} V_{t}(i)}{N_{t}(i)}\right)^{2} P_{t} Y_{t} \\
& -\frac{\phi_{P}}{2}\left(\frac{P_{t}(i)}{\pi_{t-1}^{\varsigma} \pi^{1-\varsigma} P_{t-1}(i)}-1\right)^{2} P_{t} Y_{t} \\
& -\frac{\phi_{W}}{2}\left(\frac{W_{t}(i)}{z \pi_{t-1}^{\varrho} \pi^{1-\varrho} W_{t-1}(i)}-1\right)^{2} N_{t}(i) P_{t} Y_{t}
\end{aligned}
$$

subject to the constraints

$$
\begin{aligned}
Y_{t}(i) & =\left[\frac{P_{t}(i)}{P_{t}}\right]^{-\theta_{t}} Y_{t}, \\
Y_{t}(i) & \leq K_{t}(i)^{\alpha}\left[A_{t} N_{t}(i)\right]^{1-\alpha}, \\
N_{t}(i) & =\chi N_{t-1}(i)+q_{t} V_{t}(i),
\end{aligned}
$$

where $\chi \equiv 1-\rho$ is the job survival rate. Let $\Xi_{t}(i)$ and $\Psi_{t}(i)$ denote the Lagrange multipliers on constraints (33) and (34) respectively. The multiplier $\Psi_{t}(i)$ measures the value to firm $i$, expressed in utils, of an additional job in period $t$. The multiplier $\Xi_{t}(i)$ measures the value to firm $i$, expressed in utils, of an additional unit of output. Finally, let $\xi_{t}(i) \equiv \Xi_{t}(i) / \Lambda_{t}$ denote firm $i$ 's real marginal cost in period $t$.

Wage setting Unemployment benefits $b_{t}$ are proportional to the value of the nominal wage along the balanced growth path, $W_{s s, t}$,

$$
b_{t}=\tau W_{s s, t},
$$

where $\tau$ is the replacement ratio. The fact that hiring costs and unemployment benefits both share the common stochastic trend ensures that the unemployment rate is stationary.

Jobs and workers at a given intermediate goods-producing firm are homogeneous. $W_{t}(i)$ denotes the nominal wage paid for any job at firm $i$ in period $t$. Each period $t$, the representative intermediate goods-producing firm bargains with each of its employees separately over $W_{t}(i)$. The nominal wage is determined through bilateral Nash bargaining,

$$
W_{t}(i)=\arg \max \left[S_{t}(i)^{\eta_{t}} J_{t}(i)^{1-\eta_{t}}\right]
$$

$S_{t}(i)$ denotes the surplus of the representative worker at firm $i$ while $J_{t}(i)$ is the surplus of firm $i$. Both $S_{t}(i)$ and $J_{t}(i)$ are expressed in real terms. $\eta_{t}$ denotes the worker's bargaining power which evolves exogenously according to

$$
\ln \eta_{t}=\left(1-\rho_{\eta}\right) \ln \eta+\rho_{\eta} \ln \eta_{t-1}+\varepsilon_{\eta t}
$$

where $0<\eta<1$ and $\varepsilon_{\eta t}$ is i.i.d.N $\left(0, \sigma_{\eta}^{2}\right)$. 
The worker's surplus in terms of final consumption goods is given by

$$
S_{t}(i)=\frac{W_{t}(i)}{P_{t}}-\frac{b_{t}}{P_{t}}+\beta E_{t}\left[\chi\left(1-s_{t+1}\right)\right]\left(\frac{\Lambda_{t+1}}{\Lambda_{t}}\right) S_{t+1}(i)
$$

The surplus of firm $i$ expressed in real terms is given by

$$
\begin{aligned}
J_{t}(i)= & \xi_{t}(i)(1-\alpha) \frac{Y_{t}(i)}{N_{t}(i)}-\frac{W_{t}(i)}{P_{t}}+\frac{\phi_{N} Y_{t} x_{t}(i)^{2}}{N_{t}(i)} \\
& -\frac{\phi_{W}}{2}\left(\frac{W_{t}(i)}{z \pi_{t-1}^{\varrho} \pi^{1-\varrho} W_{t-1}(i)}-1\right)^{2} Y_{t}+\beta \chi E_{t}\left[\frac{\Lambda_{t+1}}{\Lambda_{t}} J_{t+1}(i)\right] .
\end{aligned}
$$

Nash bargaining requires that the equilibrium nominal wage $W_{t}(i)$ satisfies the following firstorder condition

$$
\eta_{t} J_{t}(i) \frac{\partial S_{t}(i)}{\partial W_{t}(i)}=-\left(1-\eta_{t}\right) S_{t}(i) \frac{\partial J_{t}(i)}{\partial W_{t}(i)}
$$

where

$$
\begin{aligned}
\frac{\partial S_{t}(i)}{\partial W_{t}(i)} & =\frac{1}{P_{t}}, \\
-\frac{\partial J_{t}(i)}{\partial W_{t}(i)} & =\left\{\begin{array}{c}
\frac{1}{P_{t}}+\phi_{W} Y_{t}\left(\frac{1}{z \pi_{t-1}^{\varrho} \pi^{1-\varrho} W_{t-1}(i)}\right)\left(\frac{W_{t}(i)}{z \pi_{t-1}^{\varrho} \pi^{1-\varrho} W_{t-1}(i)}-1\right) \\
-\beta \chi \phi_{W} E_{t}\left[\frac{\Lambda_{t+1} Y_{t+1}}{\Lambda_{t} W_{t}(i)}\left(\frac{W_{t+1}(i)}{z \pi_{t-1}^{\varrho} \pi^{1-\varrho} W_{t-1}(i)}\right)\left(\frac{W_{t+1}(i)}{z \pi_{t-1}^{\varrho} \pi^{1-\varrho} W_{t-1}(i)}-1\right)\right]
\end{array}\right\} .
\end{aligned}
$$

When $\phi_{W}=0$, adjusting nominal wages is costless for the firm. In that case, the effects of a marginal increase in the nominal wage on the worker's surplus and on the firm's surplus have the same magnitude (with opposite signs):

$$
\text { if } \phi_{W}=0, \text { then } \frac{\partial S_{t}(i)}{\partial W_{t}(i)}=-\frac{\partial J_{t}(i)}{\partial W_{t}(i)}=\frac{1}{P_{t}} \text {. }
$$

In the absence of nominal wage-adjustment costs, Nash bargaining over the nominal wage implies the usual first-order condition

$$
S_{t}(i)=\left(\frac{\eta_{t}}{1-\eta_{t}}\right) J_{t}(i)
$$

Thus, as pointed out by Arsenau and Chugh (2008), Nash bargaining over the nominal wage when there are no nominal wage adjustment costs is equivalent to Nash bargaining over the real wage. The presence of nominal wage-adjustment costs (beared by the firm) affects the effective bargaining powers of the firm and the worker respectively. In the presence of nominal wage adjustment costs, the first-order condition from Nash bargaining is given by

$$
\begin{aligned}
S_{t}(i) & =\frac{\eta_{t}}{\left(1-\eta_{t}\right)} \frac{\left[\partial S_{t}(i) / \partial W_{t}(i)\right]}{\left[-\partial J_{t}(i) / \partial W_{t}(i)\right]} J_{t}(i), \\
S_{t}(i) & =\mathrm{D}_{i t} J_{t}(i),
\end{aligned}
$$


where we have introduced the notation

$$
\mathrm{D}_{i t} \equiv \frac{\left(\frac{\eta_{t}}{1-\eta_{t}}\right)\left(\frac{\partial S_{t}(i)}{\partial W_{t}(i)}\right)}{\left(-\frac{\partial J_{t}(i)}{\partial W_{t}(i)}\right)}
$$

Finally, the equation governing the dynamics of the real wage at firm $i$ is given by

$$
\begin{aligned}
\frac{W_{t}(i)}{P_{t}}= & \left(\frac{\mathrm{D}_{i t}}{1+\mathrm{D}_{i t}}\right)\left[\begin{array}{c}
\xi_{t}(i)(1-\alpha) \frac{Y_{t}(i)}{N_{t}(i)}+\frac{\phi_{N} Y_{t} x_{t}(i)^{2}}{N_{t}(i)} \\
-\frac{\phi_{W}}{2}\left(\frac{W_{t}(i)}{z \pi_{t-1}^{o} \pi^{1-\varrho} W_{t-1}(i)}-1\right)^{2} Y_{t} \\
+\beta \chi E_{t}\left(\frac{\Lambda_{t+1}}{\Lambda_{t}}\right)\left(\frac{\phi_{N} Y_{t+1} x_{t+1}(i)}{N_{t+1}(i)}\right)
\end{array}\right] \\
& +\frac{1}{\left(1+\mathrm{D}_{i t}\right)}\left[\frac{b_{t}}{P_{t}}-\beta \chi E_{t} \mathrm{D}_{i t+1}\left(1-s_{t+1}\right)\left(\frac{\Lambda_{t+1}}{\Lambda_{t}}\right)\left(\frac{\phi_{N} Y_{t+1} x_{t+1}(i)}{N_{t+1}(i)}\right)\right] .
\end{aligned}
$$

Government The central bank adjusts the short-term nominal gross interest rate $r_{t}^{B}$ by following a Taylor-type rule

$$
\begin{aligned}
\ln \left(\frac{r_{t}^{B}}{r^{B}}\right) & =\rho_{r} \ln \left(\frac{r_{t-1}^{B}}{r^{B}}\right)+\left(1-\rho_{r}\right)\left[\rho_{\pi} \ln \left(\frac{\pi_{t}}{\pi}\right)+\rho_{y} \ln \left(\frac{Y_{t} / Y_{t-1}}{z}\right)\right]+\ln \epsilon_{m p t}, \\
\ln \epsilon_{m p t} & =\rho_{m p} \ln \epsilon_{m p t-1}+\varepsilon_{m p t} .
\end{aligned}
$$

where $\pi_{t}=P_{t} / P_{t-1}$. The monetary policy shock $\epsilon_{m p t}$ follows an $\mathrm{AR}(1)$ process with $0 \leq \rho_{m p}<1$ and $\varepsilon_{m p t} \sim$ i.i.d.N $\left(0, \sigma_{m p}^{2}\right)$. The degree of interest-rate smoothing $\rho_{r}$ and the reaction coefficients $\rho_{\pi}, \rho_{y}$ are all positive.

The government budget constraint is of the form

$$
P_{t} G_{t}+\left(1-N_{t}\right) b_{t}=\left(\frac{B_{t}}{r_{t}^{B}}-B_{t-1}\right)+T_{t}
$$

where $T_{t}$ denotes total nominal lump-sum transfers. Public spending is an exogenous timevarying fraction of GDP

$$
G_{t}=\left(1-\frac{1}{\epsilon_{g t}}\right) Y_{t},
$$

where $\epsilon_{g t}$ evolves according to

$$
\ln \epsilon_{g t}=\left(1-\rho_{g}\right) \ln \epsilon_{g}+\rho_{g} \ln \epsilon_{g t-1}+\varepsilon_{g t},
$$

with $\varepsilon_{g t} \sim$ i.i.d.N $\left(0, \sigma_{g}^{2}\right)$.

Symmetric equilibrium In a symmetric equilibrium, all intermediate goods-producing firms make identical decisions, so that $Y_{t}(i)=Y_{t}, P_{t}(i)=P_{t}, N_{t}(i)=N_{t}, V_{t}(i)=V_{t}, K_{t}(i)=K_{t}$ for all $i \in[0,1]$ and $t=0,1,2, \ldots$. Moreover, workers are homogeneous and all workers at a given firm $i$ receive the same nominal wage $W_{t}(i)$, so that $W_{t}(i)=W_{t}$ for all $i \in[0,1]$ and $t=0,1,2, \ldots$. The aggregate resource constraint is obtained by aggregating the household budget constraint 
over all intermediate sectors $i \in[0,1]$,

$$
\left[\frac{1}{\epsilon_{g t}}-\frac{\phi_{N}}{2} x_{t}^{2}-\frac{\phi_{P}}{2}\left(\frac{\pi_{t}}{\pi_{t-1}^{\varsigma} \pi^{1-\varsigma}}-1\right)^{2}-\frac{\phi_{W}}{2}\left(\frac{W_{t}}{z \pi_{t-1}^{\varrho} \pi^{1-\varrho} W_{t-1}}-1\right)^{2} N_{t}\right] Y_{t}=C_{t}+I_{t}+a\left(u_{t}\right) \bar{K}_{t-1} .
$$

Model solution Real output, consumption, investment, capital and wages share the stochastic trend induced by the unit root process for neutral technological progress. In the absence of shocks, the economy converges to a steady-state growth path in which all stationary variables are constant. I first rewrite the model in terms of stationary variables, and then loglinearize the transformed economy around its deterministic steady state. The approximate model can then be solved using standard methods.

\section{Econometric strategy}

Data The estimation is based on quarterly U.S. data on seven key aggregate variables: the growth rate of real output, the growth rate of real consumption, the growth rate of real investment, the growth rate of real wages, the inflation rate, the short-term nominal interest rate and the vacancy/unemployment ratio which summarizes the tightness of the labor market and plays an important role in the Mortensen-Pissarides model. ${ }^{9}$ The model includes just as many shocks as observables. The sample period runs from 1984:QI to 2006:QI. The appendix describes the dataset in detail.

Calibrated parameters and estimation technique Because of weak identification problems, I calibrate nine parameters prior to estimation. Table 1 summarizes the calibration. The quarterly depreciation rate $\delta$ is set equal to 0.025 , a value commonly used in the literature. The capital share of output $\alpha$ is calibrated at 0.33 . The elasticity of substitution between intermediate goods $\theta$ is set equal to 6 , impliying a steady-state markup of 20 percent. The calibration of the vacancy-filling rate $q$ is just a normalization as $q$ is not identified. The government spending/output ratio $G / Y$ is set equal to 0.20 . Finally, the steady-state values of the unemployment rate $U$, the rate of inflation $\pi$, the nominal interest rate $r^{B}$, and the growth rate of output $z$, are set equal to their respective sample averages. ${ }^{10}$

I estimate the remaining 28 parameters using Bayesian techniques. ${ }^{11}$ In particular, I use the Random-Walk Metropolis-Hasting algorithm to generate 250000 draws from the posterior distribution. The algorithm is tuned to achieve an acceptance ratio between 30 and 40 percents.

\footnotetext{
${ }^{9}$ In the model, labor adjusts exclusively along the extensive margin. Data on employment or unemployment seem therefore better suited than data on total hours. Moreover, unemployment and vacancies are very persistent and strongly negatively correlated. By considering the vacancy/unemployment ratio, I exploit the Beveridge curve to remove the trend shared by unemployment and vacancies.

${ }^{10}$ The calibration of the steady-state values of the inflation rate, the nominal interest rate and output growth implies a value for the discount factor. See Table 4.

${ }^{11}$ See An and Schorfheide (2007) for an excellent review of the Bayesian estimation of DSGE models.
} 
I disregard the first 125000 draws. I then select one-every-eight draws in order to reduce the serial correlation of the chain. Finally the results presented in Tables 2 and 3 and in Figures 1 to 3 are based on 1500 draws from the posterior distribution. Prior distributions are standard and are summarized in Table 2.

Parameter estimates Table 2 reports some summary statistics of the posterior distributions of the parameters. Most parameter estimates are in line with the existing literature. The estimated degree of habit persistence in consumption is relatively low. The posterior median of the elasticity of the matching function to unemployment $\sigma$ is equal to 0.30 , consistent with the evidence provided by Blanchard and Diamond (1990) for the U.S.. The posterior median of the job destruction rate $\rho$ is equal to 0.163 . This is value is very close to the one used by Andolfatto (1996). The posterior median and 95 percentile of the replacement rate $\tau$ are respectively $27 \%$ and $46 \%{ }^{12}$ Hiring costs account for roughly 50 basis points of output.

Of particular interest for the purpose of this paper are the estimates of the coefficients of the interest rate rule which is meant to capture the behavior of the Federal Reserve over the sample period. The three coefficients are estimated relatively precisely. The degree of interest rate smoothing is roughly 0.8 . The long-run response of the central bank to deviations of inflation from the sample mean is about 2 , while the response to output growth is aproximately 0.2 . The standard deviation of the Gaussian white noise innovations to the interest-rate rule is smaller than 0.002 and greater than 0.001 . The size of the monetary policy innovations is in line with the evidence found in the existing literature thereby attesting the good fit of the estimated rule.

\section{Assessing the performance of the Federal Reserve}

In this section, I use the estimated DSGE model and data up to 2009:Q4 to back out the path of the natural rate of unemployment and to assess the performance of the Federal Reserve's interest rate policy in stabilizing inflation and the unemployment gap.

Measuring the natural rate of unemployment and the unemployment gap Following Sala et al. (2008), the natural rate of unemployment is defined as the unemployment rate under flexible prices and wages in the absence of price-markup and bargaining-power shocks. ${ }^{13}$ I construct the unemployment gap as the log-deviation of the actual unemployment rate from the model-consistent natural rate. Figure 2 and 3 show the estimates of the natural rate and the unemployment gap respectively. Shaded areas mark the NBER recessions. Interestingly the unemployment gap increases during recessions.

\footnotetext{
${ }^{12}$ These estimates do not support the calibration advocated by Hagedorn and Manovskii (2008). The estimated model relies on a nominal wage stickiness and a combination of bargaining-power shocks and price-markup shocks to solve the "volatility puzzle" highlighted by Shimer (2005).

${ }^{13}$ Price-markups shocks are inefficient because they generate variations in the degree of distortion due to monopolistic competition. Bargaining power shocks are inefficient because they generate variations in the degree of distortion due to congestion externalities. These disturbances induce time-varying deviations from the Hosios conditions. This definition of the natural rate is consistent with the concept of potential output in Justiniano and Primiceri (2008). Bargaining-power shocks in my model are similar to wage-markup shocks in Justiniano and Primiceri (2008).
} 
Historical decompositions of inflation and the unemployment gap Figure 4 and 5 show the historical decompositions of the unemployment gap and inflation. The three recessions are periods during which monetary policy shocks are expansionary. Moreover, through the lens of the model, negative risk-premium shocks have played a major role in both the 2001 and 2008 recessions. Finally, the unemployment gap was negative and was falling throughout the second half of the nineties under the effects of negative bargaining power shocks. This evidence is consistent with the belief that globalization and the increased competition from developing countries during this period had forced US industries to improve their cost-competitiveness, moderating US workers' wage increases.

Assessing monetary policy shocks What have been the effects of monetary policy shocks on fluctuations in inflation and the unemployment gap? Figure 6 shows the time series of monetary policy shocks. ${ }^{14}$ Large monetary policy shocks did occur during the three recessions. To understand the extent to which these disturbances were desirable, Figures 7 and 8 show the counterfactual path of inflation and the unemployment gap in the absence of monetary policy shocks. We observe that monetary policy shocks prevented deflation in 2002 and again in 2008. This evidence contradicts the view that monetary policy was excessively expansionary during the period 2002-2006 (See for example Taylor 2007). Instead, it clearly supports to the justification of the Federal Reserve's conduct of monetary policy advocated by Bernanke (2010) and Svensson (2009). ${ }^{15}$ Moreover, without monetary policy shocks, the magnitude of fluctuations in the unemployment gap increases substantially. These results suggest that unanticipated deviations from the Federal Reserve interest-rate rule over the last decade contributed materially to improving macroeconomic stability.

\section{$5 \quad$ Sensitivity analysis}

To be written. This section checks the robustness of the results to changes in the econometric strategy (data (Choice of observables: estimate with a different rate of inflation; sample period), estimation (measurement errors as in Justiniano and Primiceri (2008))) and in the specification of the interest-rate rule (current unemployment rate/growth/gap, current output level/growth/gap, expected unployment rate/growth/gap, expected output level/growth/gap, HP-filter output gap, HP-filter unemployment gap).

\section{Concluding remarks}

This paper estimates a medium-scale DSGE model with sticky prices and equilibrium unemployment on post-1984 quarterly US data. The model allows us to estimate the path of the natural rate of unemployment and to construct a time series for an economically meaningful measure

\footnotetext{
${ }^{14}$ These estimates are obtained with the Kalman smoother.

${ }^{15}$ The finding that the stance of monetary policy during the period 2002-2006 was not excessively accomodative is consistent with recent evidence in Justiniano and Primiceri (2010).
} 
of the unemployment gap. The estimated unemployment gap increases during each of the three recessions dated by the NBER over the period 1985:Q1 to 2009:Q4. The three recessions emerge as periods during which monetary policy shocks were expansionary. A counterfactual experiment indeed demonstrates that, in the absence of monetary policy shocks, the US economy would have experienced periods of deflation in 2002 and 2008.

The structural analysis of the current recession presented in this paper obviously suffers from several shortcomings. The introduction into the model of a housing sector and of financial intermediaries would certainly improve the congruence of the model to the recent experience. Similarly, the model cannot be used to evaluate the non-conventional monetary policy that has been adopted by the Federal Reserve during the financial crisis. It would be interesting, for future research, to examine how the introduction of such features would affect our findings. 


\section{Appendix: Description of the database}

The estimation is based on seven variables: per capita output, consumption and investment in real terms, real wages, labor market tightness (i.e. the ratio of vacancy over unemployment), inflation and the nominal short-term interest rate. I use quarterly U.S. data. All series are downloaded from the FRED database. Following Justiniano, Primiceri and Tambalotti (2010), I measure nominal consumption using data on nominal personal consumption expenditures of nondurables and services. Nominal investment corresponds to the sum of personal consumption expenditures of durables and gross private domestic investment. Nominal output is measured by nominal GDP. Per capita real GDP, consumption and investment are obtained by dividing the nominal series by the GDP deflator and population. Real wages corresponds to nominal compensation per hour in the non-farm business sector, divided by the GDP deflator. Consistently with the model, I measure population by the labor force which is itself defined as the sum of official unemployment and official employment. The vacancy rate is measured by the index of Help wanted advertising in newspapers divided by labor force. The unemployment rate is the ratio of official unemployment over labor force. Labor market tightness is the ratio of the vacancy rate over the unemployment rate. Inflation is the first difference of the log of the GDP deflator. The nominal interest rate is measured by the effective Federal Funds rate. 


\section{References}

An, S. and Schorfheide, F. (2007), 'Bayesian analysis of DSGE models', Econometric Reviews 26(2-4), 113-172.

Andolfatto, D. (1996), 'Business cycles and labor market search', American Economic Review 86(1), 112-132.

Arsenau, D. and Chugh, S. (2008), 'Optimal fiscal and monetary policy with costly wage bargaining', Journal of Monetary Economics 55, 1401-1414.

Barro, R. (1977), 'Long-term contracting, sticky prices, and monetary policy', Journal of Monetary Economics 3(3), 305-316.

Bernanke, B. (2010), 'Monetary policy and the housing bubble', Speech at the annual meeting of the American Economic Association, Atlanta, January 3, 2010 .

Blanchard, O. and Diamond, P. (1990), 'The aggregate matching function', Productivity/Growth/Unemployment MIT Press.

Chari, V. V., McGrattan, E. and Kehoe, P. (2007), 'Business cycle accounting', Econometrica 75(3), 781-836.

Christiano, L., Eichenbaum, M. and Evans, C. (2005), 'Nominal rigidities and the dynamics effects of a shock to monetary policy', Journal of Political Economy 113(1), 1-45.

De Graeve, F., Emiris, M. and Wouters, R. (2009), 'A structural decomposition of the US yield curve', Journal of Monetary Economics 56, 545-559.

Dokko, J., Doyle, B., Kiley, M., Kim, J., Sherlund, S., Sim, J. and van den Heuvel, S. (2009), 'Monetary policy and the housing bubble', Federal Reserve Board, FEDS working paper 2009-49.

Gertler, M., Sala, L. and Trigari, A. (2008), 'An estimated monetary DSGE model with unemployment and staggered nominal wage bargaining', Journal of Money, Credit and Banking 40(8), 1713-1764.

Groshenny, N. (2009), 'Evaluating a monetary business cycle model with unemployment for the euro area', National Bank of Belgium Working Papers 173.

Hagedorn, M. and Manovskii, I. (2008), 'The cyclical behavior of equilibrium unemployment and vacancies revisited', American Economic Review 98(4), 1692-1706.

Hall, R. (1997), 'Macroeconomic fluctuations and the allocation of time', Journal of Labor Economics 15(1), S223-S250.

Ireland, P. (2007), 'Changes in the Federal Reserve's inflation target: Causes and consequences', Journal of Money, Credit and Banking 39(8), 1851-1882. 
Justiniano, A. and Primiceri, G. (2008), 'Potential and natural output', mimeo, Northwestern University .

Justiniano, A. and Primiceri, G. (2010), 'Measuring the equilibrium real interest rate', Federal Reserve Bank of Chicago, Economic Perspectives 34(1), 14-27.

Justiniano, A., Primiceri, G. and Tambalotti, A. (2010), 'Investment shocks and business cycles', Journal of Monetary Economics 57, 132-145.

Krause, M. and Lubik, T. (2007), 'The (ir)relevance of real wage rigidity in the new Keynesian model with search frictions', Journal of Monetary Economics 54(3), 706-727.

Merz, M. (1995), 'Search in the labor market and the real business cycle', Journal of Monetary Economics 36, 269-300.

Pissarides, C. (2000), 'Equilibrium unemployment theory', MIT Press .

Sala, L., Söderström, U. and Trigari, A. (2008), 'Monetary policy under uncertainty in an estimated model with labor market frictions', Journal of Monetary Economics 55(5), 9831006.

Sala, L., Söderström, U. and Trigari, A. (2010), 'Potential output, the output gap and the labor wedge', mimeo, Bocconi University .

Shimer, R. (2005), 'The cyclical behavior of equilibrium unemployment and vacancies: Evidence and theory', American Economic Review 95(1), 25-49.

Smets, F. and Wouters, R. (2007), 'Shocks and frictions in US business cycles: A Bayesian DSGE approach', American Economic Review 97(3), 586-606.

Sveen, T. and Weinke, L. (2008), 'Inflation and labor market dynamics revisited', Kiel Institute Working Paper 1368.

Svensson, L. (2009), 'Flexible inflation targeting: Lessons from the financial crisis', Speech at De Nederlandsche Bank, Amsterdam, September 21, 2009.

Taylor, J. (2007), 'Housing and monetary policy', Federal Reserve Bank of Kansas City in Jackson Hole .

Trigari, A. (2009), 'Equilibrium unemployment, job flows and inflation dynamics', Journal of Money, Credit and Banking 41 (1), 1-33.

Walsh, C. (2005), 'Labor market search, sticky prices and interest rate rules', Review of Economic Dynamics 8, 829-849.

Yashiv, E. (2006), 'Evaluating the performance of the search and matching model', European Economic Review 50(4), 909-936. 
Table 1: Calibrated parameters

\begin{tabular}{lcc}
\hline \hline Capital depreciation rate & $\delta$ & 0.0250 \\
Capital share & $\alpha$ & 0.33 \\
Elasticity of substitution btw goods & $\theta$ & 6.00 \\
Probability to fill a vacancy within a quarter & $q$ & 0.7000 \\
Exogenous spending/output ratio & $g / y$ & 0.2000 \\
Unemployment rate & $U$ & 0.0575 \\
Quarterly growth rate & $z$ & 1.0044 \\
Quarterly inflation rate & $\pi$ & 1.0062 \\
Quarterly nominal interest rate & $r^{B}$ & 1.0129 \\
\hline \hline
\end{tabular}


Table 2: Prior and posterior distributions of structural parameters

\begin{tabular}{|c|c|c|c|c|c|c|}
\hline & & \multirow{2}{*}{$\begin{array}{c}\text { Prior } \\
\text { distribution }\end{array}$} & \multicolumn{4}{|c|}{ Posterior distributions } \\
\hline & & & Median & Std dev & $5 \%$ & $95 \%$ \\
\hline Job destruction rate & $\rho$ & Normal $(0.07,0.02)$ & 0.163 & 0.015 & 0.137 & 0.188 \\
\hline Replacement rate & $10 \tau$ & Normal $(5,2)$ & 2.745 & 1.284 & 0.275 & 4.584 \\
\hline Hiring cost/output ratio & $1000 \frac{\phi_{N}}{2} x^{2}$ & Normal $(5,0.5)$ & 4.642 & 0.428 & 3.887 & 5.362 \\
\hline Habit persistence in comsump. & $h$ & Beta $(0.65,0.15)$ & 0.477 & 0.045 & 0.398 & 0.542 \\
\hline Elasticity of matches to unemp. & $\sigma$ & $\operatorname{Beta}(0.6,0.1)$ & 0.307 & 0.047 & 0.228 & 0.3834 \\
\hline Investment adjustment cost & $\phi_{I}$ & Normal $(5,1)$ & 1.246 & 0.421 & 0.714 & 2.061 \\
\hline Capital utilization cost & $\phi_{u 2}$ & Normal $(0.5,0.15)$ & 0.587 & 0.106 & 0.439 & 0.791 \\
\hline Price adjustment cost & $\phi_{P}$ & IGamma $(80,40)$ & 41.63 & 7.506 & 32.32 & 57.81 \\
\hline Wage adjustment cost & $\phi_{W}$ & IGamma $(20,20)$ & 10.75 & 2.814 & 7.407 & 17.21 \\
\hline Price indexation & $\varsigma$ & Beta $(0.5,0.2)$ & 0.166 & 0.063 & 0.085 & 0.288 \\
\hline Wage indexation & $\varrho$ & Beta $(0.5,0.2)$ & 0.599 & 0.166 & 0.295 & 0.822 \\
\hline Interest rate smoothing & $\rho_{r}$ & Beta $(0.7,0.15)$ & 0.801 & 0.022 & 0.758 & 0.834 \\
\hline Response to inflation & $\rho_{\pi}$ & Normal $(1.5,0.2)$ & 2.136 & 0.117 & 1.921 & 2.328 \\
\hline Response to output growth & $\rho_{y}$ & Normal $(0.15,0.05)$ & 0.217 & 0.040 & 0.155 & 0.282 \\
\hline
\end{tabular}


Table 3: Prior and posterior distributions of shock parameters

\begin{tabular}{lllcccc}
\hline \hline & & Prior & \multicolumn{4}{c}{ Posterior distributions } \\
\cline { 5 - 7 } & & distribution & Median & Std dev & $5 \%$ & $95 \%$ \\
\hline Technology growth & $\rho_{z}$ & Beta $(0.35,0.15)$ & 0.182 & 0.064 & 0.078 & 0.289 \\
Technology growth & $100 \sigma_{z}$ & IGamma $(0.1,2)$ & 0.756 & 0.054 & 0.678 & 0.851 \\
Monetary policy & $\rho_{m p}$ & Beta $(0.5,0.2)$ & 0.483 & 0.183 & 0.195 & 0.808 \\
Monetary policy & $100 \sigma_{m p}$ & IGamma $(0.1,2)$ & 0.150 & 0.013 & 0.132 & 0.176 \\
Investment & $\rho_{\mu}$ & Beta $(0.5,0.2)$ & 0.940 & 0.022 & 0.900 & 0.969 \\
Investment & $100 \sigma_{\mu}$ & IGamma $(0.1,2)$ & 1.886 & 0.293 & 1.450 & 2.476 \\
Risk-premium & $\rho_{b}$ & Beta $(0.5,0.2)$ & 0.946 & 0.017 & 0.914 & 0.972 \\
Risk-premium & $100 \sigma_{b}$ & IGamma $(0.1,2)$ & 0.107 & 0.017 & 0.085 & 0.143 \\
Price markup & $\rho_{\theta}$ & Beta $(0.5,0.2)$ & 0.845 & 0.042 & 0.764 & 0.905 \\
Price markup & $100 \sigma_{\theta}$ & IGamma $(0.1,2)$ & 0.129 & 0.015 & 0.103 & 0.153 \\
Bargaining power & $\rho_{\eta}$ & Beta $(0.5,0.2)$ & 0.550 & 0.077 & 0.399 & 0.660 \\
Bargaining power & $100 \sigma_{\eta}$ & IGamma $(0.1,2)$ & 14.41 & 2.765 & 11.16 & 19.63 \\
Government spending & $\rho_{g}$ & Beta $(0.7,0.2)$ & 0.969 & 0.012 & 0.946 & 0.983 \\
Government spending & $100 \sigma_{g}$ & IGamma $(0.1,2)$ & 0.353 & 0.023 & 0.317 & 0.390 \\
\hline \hline
\end{tabular}


Table 4: Parameters derived from steady-state conditions

\begin{tabular}{|c|c|c|}
\hline Employment adjustment cost & $\phi_{N}$ & $\phi_{N}=\frac{2 \times\left(\frac{\phi_{N}}{2} x^{2}\right)}{x^{2}}$ \\
\hline Discount factor & $\beta$ & $\beta=\frac{z \pi}{r^{B}}$ \\
\hline Job survival rate & $\chi$ & $\chi=1-\rho$ \\
\hline Employment rate & $N$ & $N=1-U$ \\
\hline Hiring rate & $x$ & $x=\rho$ \\
\hline Mean of exogenous spending shock & $\epsilon_{g}$ & $\epsilon_{g}=\frac{1}{1-g / y}$ \\
\hline Real marginal cost & $\xi$ & $\xi=\frac{\theta-1}{\theta}$ \\
\hline Quarterly net real rental rate of capital & $\widetilde{r}^{K}$ & $\widetilde{r}^{K}=\frac{z}{\beta}-1+\delta$ \\
\hline Capital utilization cost first parameter & $\phi_{u 1}$ & $\phi_{u 1}=\widetilde{r}^{K}$ \\
\hline Capital/output ratio & $k / y$ & $\frac{k}{y}=\frac{\alpha \xi}{\widetilde{r}^{K}}$ \\
\hline Investment/capital ratio & $i / k$ & $\frac{i}{k}=z-1+\delta$ \\
\hline Investment/output ratio & $i / y$ & $\frac{i}{y}=\frac{i}{k} \frac{k}{y}$ \\
\hline Consumption/output ratio & $c / y$ & $\frac{c}{y}=\frac{1}{\epsilon_{g}}-\frac{\phi_{N}}{2} x^{2}-\frac{i}{y}$ \\
\hline Vacancies & $V$ & $V=N \frac{x}{q}$ \\
\hline Pool of job seekers & $S$ & $S=1-\chi N$ \\
\hline Matching function efficiency & $\zeta$ & $\zeta=q\left(\frac{V}{S}\right)^{\sigma}$ \\
\hline Job finding rate & $s$ & $s=\zeta\left(\frac{V}{S}\right)^{1-\sigma}$ \\
\hline Employees' share of output & $\widetilde{w} n / y$ & $\frac{\widetilde{w} N}{y}=\xi(1-\alpha)-(1-x-\beta \chi) \phi_{N} x$ \\
\hline Bargaining power & $\eta$ & $\eta=\frac{1-\tau}{\vartheta-\tau}$ where $\vartheta \equiv \frac{\left[\xi(1-\alpha)+\phi_{N} x^{2}+\beta \chi \phi_{N} x s\right]}{\frac{\tilde{w} N}{y}}$ \\
\hline Effective bargaining power & $\mathrm{D}$ & $\mathrm{D}=\frac{\eta}{1-\eta}$ \\
\hline
\end{tabular}




\section{Technical appendix}

\section{The symmetric equilibrium}

In a symmetric equilibrium, $Y_{t}(i)=Y_{t}, P_{t}(i)=P_{t}, N_{t}(i)=N_{t}, V_{t}(i)=V_{t}, K_{t}(i)=K_{t}$, $W_{t}(i)=W_{t}$ for all $i \in[0,1]$ and $t=0,1,2, \ldots$.Defining the real wage $\widetilde{W}_{t}=W_{t} / P_{t}$, the gross rate of price inflation $\pi_{t}=P_{t} / P_{t-1}$, the system of equilibrium conditions becomes

1. $Y_{t}$

$$
\begin{aligned}
& {\left[\frac{1}{\epsilon_{g t}}-\frac{\phi_{N}}{2} x_{t}^{2}-\frac{\phi_{P}}{2}\left(\frac{\pi_{t}}{\pi_{t-1}^{\varsigma} \pi^{1-\varsigma}}-1\right)^{2}-\frac{\phi_{W}}{2}\left(\frac{W_{t}}{z \pi_{t-1}^{\varrho} \pi^{1-\varrho} W_{t-1}}-1\right)^{2} N_{t}\right] Y_{t} } \\
= & C_{t}+I_{t}+\left[\phi_{u 1}\left(u_{t}-1\right)+\frac{\phi_{u 2}}{2}\left(u_{t}-1\right)^{2}\right] \bar{K}_{t-1}
\end{aligned}
$$

2. $K_{t}$

$$
K_{t}=u_{t} \bar{K}_{t-1}
$$

3. $\bar{K}_{t}$

$$
\bar{K}_{t}=(1-\delta) \bar{K}_{t-1}+\mu_{t}\left[1-\frac{\phi_{I}}{2}\left(\frac{I_{t}}{I_{t-1}}-g_{I}\right)^{2}\right] I_{t}
$$

4. $\mu_{t}$

$$
\ln \left(\mu_{t}\right)=\rho_{\mu} \ln \left(\mu_{t-1}\right)+\varepsilon_{\mu t}
$$

5. $\epsilon_{b t}$

$$
\ln \left(\epsilon_{b t}\right)=\rho_{b} \ln \left(\epsilon_{b t-1}\right)+\varepsilon_{b t}
$$

6. $\Lambda_{t}$

$$
\Lambda_{t}=\beta \epsilon_{b t} r_{t}^{B} E_{t}\left(\frac{\Lambda_{t+1}}{\pi_{t+1}}\right)
$$

7. $C_{t}$

$$
\Lambda_{t}=\frac{1}{C_{t}-h C_{t-1}}-\beta h E_{t}\left(\frac{1}{C_{t+1}-h C_{t}}\right)
$$


8. $\widetilde{r}_{t}^{K}=\frac{r_{t}^{K}}{P_{t}}$

$$
\left(\phi_{u 1}-\phi_{u 2}\right)+\phi_{u 2} u_{t}=\widetilde{r}_{t}^{K}
$$

9. $I_{t}$

$$
\begin{aligned}
1= & v_{t} \mu_{t}\left[1-\frac{\phi_{I}}{2}\left(\frac{I_{t}}{I_{t-1}}-g_{I}\right)^{2}-\phi_{I}\left(\frac{I_{t}}{I_{t-1}}-g_{I}\right)\left(\frac{I_{t}}{I_{t-1}}\right)\right] \\
& +\beta E_{t} v_{t+1} \mu_{t+1} \frac{\Lambda_{t+1}}{\Lambda_{t}} \phi_{I}\left(\frac{I_{t+1}}{I_{t}}-g_{I}\right)\left(\frac{I_{t+1}}{I_{t}}\right)^{2}
\end{aligned}
$$

10. $v_{t}=\frac{\Upsilon_{t}}{\Lambda_{t}}$

$$
v_{t}=\beta E_{t}\left\{\frac{\Lambda_{t+1}}{\Lambda_{t}}\left[(1-\delta) v_{t+1}+\widetilde{r}_{t+1}^{K} u_{t+1}-a\left(u_{t+1}\right)\right]\right\}
$$

11. $\theta_{t}$

$$
\ln \left(\theta_{t}\right)=\left(1-\rho_{\theta}\right) \ln (\theta)+\rho_{\theta} \ln \left(\theta_{t-1}\right)+\varepsilon_{\theta t}
$$

12. $N_{t}$

$$
N_{t}=\chi N_{t-1}+q_{t} V_{t}
$$

13. $S_{t}$

$$
S_{t}=1-\chi N_{t-1}
$$

14. $U_{t}$

$$
U_{t}=1-N_{t}
$$

15. $V_{o} S_{t}$

$$
V o S_{t}=\frac{V_{t}}{S_{t}}
$$

16. $\Theta_{t}=\frac{V_{t}}{U_{t}}$

$$
\Theta_{t}=\frac{V_{t}}{U_{t}}
$$


17. $V_{t}$

$$
x_{t} \equiv \frac{q_{t} V_{t}}{N_{t}}
$$

18. $q_{t}$

$$
q_{t}=\zeta\left[\frac{S_{t}}{V_{t}}\right]^{\sigma}
$$

19. $s_{t}$

$$
s_{t}=\zeta\left[\frac{V_{t}}{S_{t}}\right]^{1-\sigma}
$$

20. $x_{t}$

$$
\begin{aligned}
\phi_{N} x_{t}\left(1-x_{t}\right)= & \xi_{t}(1-\alpha)-\widetilde{W}_{t} \frac{N_{t}}{Y_{t}}-\frac{\phi_{W}}{2}\left(\frac{W_{t}}{z \pi_{t-1}^{\varrho} \pi^{1-\varrho} W_{t-1}}-1\right)^{2} N_{t} \\
& +\beta \chi \phi_{N} E_{t}\left(\frac{\Lambda_{t+1}}{\Lambda_{t}}\right)\left(\frac{N_{t}}{N_{t+1}}\right)\left(\frac{Y_{t+1}}{Y_{t}}\right) x_{t+1}
\end{aligned}
$$

21. $u_{t}$

$$
Y_{t}=A_{t}^{1-\alpha} K_{t}^{\alpha} N_{t}^{1-\alpha}
$$

22. $A_{t}$

$$
z_{t}=\frac{A_{t}}{A_{t-1}}
$$

23. $z_{t}=\frac{A_{t}}{A_{t-1}}$

$$
\ln \left(z_{t}\right)=\left(1-\rho_{z}\right) \ln (z)+\rho_{z} \ln \left(z_{t-1}\right)+\varepsilon_{z t}
$$

24. $\xi_{t}=\frac{\Xi_{t}}{\Lambda_{t}}$

$$
\widetilde{r}_{t}^{K}=\left(\alpha \frac{Y_{t}}{K_{t}}\right) \xi_{t}
$$

25. $\pi_{t}$

$$
\begin{aligned}
0= & \left(1-\theta_{t}\right)+\theta_{t} \xi_{t}-\phi_{P}\left(\frac{\pi_{t}}{\pi_{t-1}^{\varsigma} \pi^{1-\varsigma}}-1\right)\left(\frac{\pi_{t}}{\pi_{t-1}^{\varsigma} \pi^{1-\varsigma}}\right) \\
& +\beta \phi_{P} E_{t}\left[\left(\frac{\Lambda_{t+1}}{\Lambda_{t}}\right)\left(\frac{\pi_{t+1}}{\pi_{t}^{\varsigma} \pi^{1-\varsigma}}-1\right)\left(\frac{\pi_{t+1}}{\pi_{t}^{\varsigma} \pi^{1-\varsigma}}\right)\left(\frac{Y_{t+1}}{Y_{t}}\right)\right]
\end{aligned}
$$


26. $\widetilde{b}_{t}=\frac{b_{t}}{P_{t}}$

$$
\widetilde{b}_{t}=\tau \widetilde{W}_{s s, t}
$$

27. $\widetilde{W_{t}}=\frac{W_{t}}{P_{t}}$

$$
\begin{aligned}
\widetilde{W}_{t}= & \left(\frac{\mathrm{D}_{t}}{1+\mathrm{D}_{t}}\right)\left[\begin{array}{c}
\xi_{t}(1-\alpha) \frac{Y_{t}}{N_{t}}+\phi_{N} \frac{Y_{t}}{N_{t}} x_{t}^{2}-\frac{\phi_{W}}{2}\left(\frac{W_{t}}{z \pi_{t-1}^{o} \pi^{1-\varrho} W_{t-1}}-1\right)^{2} Y_{t} \\
+\beta \chi \phi_{N} E_{t} \frac{\Lambda_{t+1}}{\Lambda_{t}} \frac{Y_{t+1}}{N_{t+1}} x_{t+1}
\end{array}\right] \\
& +\frac{1}{\left(1+\mathrm{D}_{t}\right)}\left[\widetilde{b}_{t}-\beta \chi \phi_{N} E_{t} \mathrm{\bigcap}_{t+1}\left(1-s_{t+1}\right) \frac{\Lambda_{t+1}}{\Lambda_{t}} \frac{Y_{t+1}}{N_{t+1}} x_{t+1}\right]
\end{aligned}
$$

28. $\mathrm{D}_{t}$

$\mathrm{D}_{t}=\frac{\left(\frac{\eta_{t}}{1-\eta_{t}}\right)\left(\frac{\widetilde{W}_{t}}{Y_{t}}\right)}{\frac{\widetilde{W}_{t}}{Y_{t}}+\phi_{W}\left(\frac{W_{t}}{z \pi_{t-1}^{\varrho} \pi^{1-\varrho} W_{t-1}}-1\right)\left(\frac{W_{t}}{z \pi_{t-1}^{\varrho} \pi^{1-\varrho} W_{t-1}}\right)-\beta \chi \phi_{W} E_{t}\left[\frac{\Lambda_{t+1}}{\Lambda_{t}}\left(\frac{W_{t+1}}{z \pi_{t}^{\varrho} \pi^{1-\varrho} W_{t}}-1\right)\left(\frac{W_{t+1}}{z \pi_{t}^{\varrho} \pi^{1-\varrho} W_{t}}\right) \frac{Y_{t+1}}{Y_{t}}\right]}$

29. $\eta_{t}$

$$
\ln \eta_{t}=\left(1-\rho_{\eta}\right) \ln \eta+\rho_{\eta} \ln \eta_{t-1}+\varepsilon_{\eta t}
$$

30. $r_{t}^{B}$

$$
\ln \left(\frac{r_{t}^{B}}{r^{B}}\right)=\rho_{r} \ln \left(\frac{r_{t-1}^{B}}{r^{B}}\right)+\left(1-\rho_{r}\right)\left[\rho_{\pi} \ln \left(\frac{\pi_{t}}{\pi}\right)+\rho_{y} \ln \left(\frac{Y_{t}}{Y_{t-1}}\right)\right]+\ln \epsilon_{m p t}
$$

31. $\epsilon_{r t}$

$$
\ln \epsilon_{m p t}=\rho_{m p} \ln \epsilon_{m p t-1}+\varepsilon_{m p t}
$$

32. $G_{t}$

$$
G_{t}=\left(1-\frac{1}{\epsilon_{g t}}\right) Y_{t}
$$

33. $\epsilon_{g t}$

$$
\ln \epsilon_{g t}=\left(1-\rho_{g}\right) \ln \epsilon_{g}+\rho_{g} \ln \epsilon_{g t-1}+\varepsilon_{g t}
$$

34. $g y_{t}$

$$
g y_{t}=Y_{t} / Y_{t-1}
$$


35. $g c_{t}$

$$
g c_{t}=C_{t} / C_{t-1}
$$

36. $g i_{t}$

$$
g i_{t}=I_{t} / I_{t-1}
$$

37. $g w_{t}$

$$
g w_{t}=\widetilde{W}_{t} / \widetilde{W}_{t-1}
$$

These 37 equations determine equilibrium values for the 37 variables $Y_{t}, K_{t}, \bar{K}_{t}, u_{t}, C_{t}$, $\Lambda_{t}, r_{t}^{B}, G_{t}, I_{t}, v_{t}, \widetilde{r}_{t}^{K}, \xi_{t}, N_{t}, S_{t}, U_{t}, V_{t}, V o S_{t}, \Theta_{t}, q_{t}, s_{t}, x_{t}, \widetilde{W}_{t}, \mathrm{D}_{t}, \widetilde{b}_{t}, \pi_{t}, \mu_{t}, \epsilon_{b t}, A_{t}, z_{t}, \theta_{t}$, $\eta_{t}, \epsilon_{m p t}, \epsilon_{g t}, g y_{t}, g c_{t}, g i_{t}, g w_{t}$.

\section{The transformed stationary economy}

Output, consumption, investment, capital and the real wage share the stochastic trend induced by the unit root process of neutral technological progress. I first rewrite the model in terms of stationary variables, and then loglinearize this transformed model economy around its steady state. This approximate model can then be solved using standard methods. The following variables are stationary and need not to be transformed: $u_{t}, r_{t}^{B}, \widetilde{r}_{t}^{K}, v_{t}=\frac{\Upsilon_{t}}{\Lambda_{t}}, \xi_{t}, N_{t}, S_{t}, U_{t}$, $V_{t}, q_{t}, s_{t}, x_{t}, \pi_{t}=\frac{P_{t}}{P_{t-1}}, \mu_{t}, \epsilon_{b t}, z_{t}, \theta_{t}, \eta_{t}, \epsilon_{m p t}, \epsilon_{g t}$ and $\eta_{t}$. I define the transformed variables $y_{t}=Y_{t} / A_{t}, k_{t}=K_{t} / A_{t}, \bar{k}_{t}=\bar{K}_{t} / A_{t}, c_{t}=C_{t} / A_{t}, \lambda_{t}=A_{t} \Lambda_{t}, i_{t}=I_{t} / A_{t}, \widetilde{w}_{t}=\widetilde{W}_{t} / A_{t}, \widetilde{\mathbf{b}}_{t}=\widetilde{b}_{t} / A_{t}$, $g_{t}=G_{t} / A_{t}$. The stationarized economy contains only 36 equations in 36 variables because the level of the non-stationary productivity shock $A_{t}$ is not included.

1. $y_{t}=Y_{t} / A_{t}$

$$
\begin{aligned}
& {\left[\frac{1}{\epsilon_{g t}}-\frac{\phi_{N}}{2} x_{t}^{2}-\frac{\phi_{P}}{2}\left(\frac{\pi_{t}}{\pi_{t-1}^{\varsigma} \pi^{1-\varsigma}}-1\right)^{2}-\frac{\phi_{W}}{2}\left(\frac{W_{t}}{z \pi_{t-1}^{\varrho} \pi^{1-\varrho} W_{t-1}}-1\right)^{2} N_{t}\right] y_{t} } \\
= & c_{t}+i_{t}+\left[\phi_{u 1}\left(u_{t}-1\right)+\frac{\phi_{u 2}}{2}\left(u_{t}-1\right)^{2}\right] \bar{k}_{t-1} \frac{1}{z_{t}}
\end{aligned}
$$

2. $k_{t}=K_{t} / A_{t}$

$$
k_{t}=u_{t} \bar{k}_{t-1} \frac{1}{z_{t}}
$$


3. $\bar{k}_{t}=\bar{K}_{t} / A_{t}$

$$
\bar{k}_{t}=(1-\delta) \bar{k}_{t-1} \frac{1}{z_{t}}+\mu_{t}\left[1-\frac{\phi_{I}}{2}\left(\frac{i_{t}}{i_{t-1}} z_{t}-g_{I}\right)^{2}\right] i_{t}
$$

4. $\mu_{t}$

$$
\ln \left(\mu_{t}\right)=\rho_{\mu} \ln \left(\mu_{t-1}\right)+\varepsilon_{\mu t}
$$

5. $\epsilon_{b t}$

$$
\ln \left(\epsilon_{b t}\right)=\rho_{b} \ln \left(\epsilon_{b t-1}\right)+\varepsilon_{b t}
$$

6. $\lambda_{t}=A_{t} \Lambda_{t}$

$$
\lambda_{t}=\beta \epsilon_{b t} r_{t}^{B} E_{t}\left(\frac{\lambda_{t+1}}{\pi_{t+1}} \frac{1}{z_{t+1}}\right)
$$

7. $c_{t}=C_{t} / A_{t}$

$$
\lambda_{t}=\frac{z_{t}}{z_{t} c_{t}-h c_{t-1}}-\beta h E_{t}\left(\frac{1}{c_{t+1} z_{t+1}-h c_{t}}\right)
$$

8. $\widetilde{r}_{t}^{K}=\frac{r_{t}^{K}}{P_{t}}$

$$
\left(\phi_{u 1}-\phi_{u 2}\right)+\phi_{u 2} u_{t}=\widetilde{r}_{t}^{K}
$$

9. $i_{t}=I_{t} / A_{t}$

$$
\begin{aligned}
1= & v_{t} \mu_{t}\left[1-\frac{\phi_{I}}{2}\left(\frac{i_{t}}{i_{t-1}} z_{t}-g_{I}\right)^{2}-\phi_{I}\left(\frac{i_{t}}{i_{t-1}} z_{t}-g_{I}\right)\left(\frac{i_{t}}{i_{t-1}} z_{t}\right)\right] \\
& +\beta E_{t} v_{t+1} \mu_{t+1} \frac{\lambda_{t+1}}{\lambda_{t}} \frac{1}{z_{t+1}} \phi_{I}\left(\frac{i_{t+1}}{i_{t}} z_{t+1}-g_{I}\right)\left(\frac{i_{t+1}}{i_{t}} z_{t+1}\right)^{2}
\end{aligned}
$$

10. $v_{t}=\frac{\Upsilon_{t}}{\Lambda_{t}}$

$$
v_{t}=\beta E_{t}\left\{\frac{\lambda_{t+1}}{\lambda_{t}} \frac{1}{z_{t+1}}\left[(1-\delta) v_{t+1}+\widetilde{r}_{t+1}^{K} u_{t+1}-\phi_{u 1}\left(u_{t+1}-1\right)-\frac{\phi_{u 2}}{2}\left(u_{t+1}-1\right)^{2}\right]\right\}
$$

11. $u_{t}$

$$
y_{t}=k_{t}^{\alpha} N_{t}^{1-\alpha}
$$


12. $z_{t}=\frac{A_{t}}{A_{t-1}}$

$$
\ln \left(z_{t}\right)=\left(1-\rho_{z}\right) \ln (z)+\rho_{z} \ln \left(z_{t-1}\right)+\varepsilon_{z t}
$$

13. $\xi_{t} \equiv \frac{\Xi_{t}}{\Lambda_{t}}$

$$
\widetilde{r}_{t}^{K}=\alpha \frac{y_{t}}{k_{t}} \xi_{t}
$$

14. $N_{t}$

$$
N_{t}=\chi N_{t-1}+q_{t} V_{t}
$$

15. $S_{t}$

$$
S_{t}=1-\chi N_{t-1}
$$

16. $U_{t}$

$$
U_{t}=1-N_{t}
$$

17. $V o S_{t}$

$$
V o S_{t}=\frac{V_{t}}{S_{t}}
$$

18. $\Theta_{t}=\frac{V_{t}}{U_{t}}$

$$
\Theta_{t}=\frac{V_{t}}{U_{t}}
$$

19. $q_{t}$

$$
q_{t}=\zeta\left[\frac{S_{t}}{V_{t}}\right]^{\sigma}
$$

20. $s_{t}$

$$
s_{t}=\zeta\left[\frac{V_{t}}{S_{t}}\right]^{1-\sigma}
$$

21. $V_{t}$

$$
x_{t} \equiv \frac{q_{t} V_{t}}{N_{t}}
$$


22. $x_{t}$

$$
\begin{aligned}
\phi_{N} x_{t}\left(1-x_{t}\right)= & \xi_{t}(1-\alpha)-\widetilde{w}_{t} \frac{N_{t}}{y_{t}}-\frac{\phi_{W}}{2}\left(\frac{W_{t}}{z \pi_{t-1}^{\varrho} \pi^{1-\varrho} W_{t-1}}-1\right)^{2} N_{t} \\
& +\beta \chi \phi_{N} E_{t}\left(\frac{\lambda_{t+1}}{\lambda_{t}} \frac{N_{t}}{N_{t+1}} \frac{y_{t+1}}{y_{t}} x_{t+1}\right)
\end{aligned}
$$

23. $\theta_{t}$

$$
\ln \left(\theta_{t}\right)=\left(1-\rho_{\theta}\right) \ln (\theta)+\rho_{\theta} \ln \left(\theta_{t-1}\right)+\varepsilon_{\theta t}
$$

24. $\pi_{t}=\frac{P_{t}}{P_{t-1}}$

$$
\begin{aligned}
0= & \left(1-\theta_{t}\right)+\theta_{t} \xi_{t}-\phi_{P}\left(\frac{\pi_{t}}{\pi_{t-1}^{\varsigma} \pi^{1-\varsigma}}-1\right)\left(\frac{\pi_{t}}{\pi_{t-1}^{\varsigma} \pi^{1-\varsigma}}\right) \\
& +\beta \phi_{P} E_{t}\left[\frac{\lambda_{t+1}}{\lambda_{t}}\left(\frac{\pi_{t+1}}{\pi_{t}^{\varsigma} \pi^{1-\varsigma}}-1\right)\left(\frac{\pi_{t+1}}{\pi_{t}^{\varsigma} \pi^{1-\varsigma}}\right) \frac{y_{t+1}}{y_{t}}\right]
\end{aligned}
$$

25. $\widetilde{\mathbf{b}}_{t}=\widetilde{b}_{t} / A_{t}$

$$
\widetilde{\mathbf{b}}_{t}=\widetilde{\mathbf{b}}=\tau \widetilde{w}
$$

26. $\widetilde{w}_{t}=\widetilde{W}_{t} / A_{t}$

$$
\begin{aligned}
& \widetilde{w}_{t}=\left(\frac{D_{t}}{1+D_{t}}\right)\left[\begin{array}{c}
\xi_{t}(1-\alpha) \frac{y_{t}}{N_{t}}+\phi_{N} \frac{y_{t}}{N_{t}} x_{t}^{2}-\frac{\phi_{W}}{2}\left(\frac{W_{t}}{z \pi_{t-1}^{o} \pi^{1-\varrho} W_{t-1}}-1\right)^{2} y_{t} \\
+\beta \chi \phi_{N} E_{t} \frac{\lambda_{t+1}}{\lambda_{t}} \frac{y_{t+1}}{N_{t+1}} x_{t+1}
\end{array}\right] \\
& +\frac{1}{\left(1+\mathrm{D}_{t}\right)}\left[\widetilde{\mathbf{b}}-\beta \chi \phi_{N} E_{t} \mathrm{円}_{t+1}\left(1-s_{t+1}\right) \frac{\lambda_{t+1}}{\lambda_{t}} \frac{y_{t+1}}{N_{t+1}} x_{t+1}\right]
\end{aligned}
$$

27. $\mathrm{D}_{t}$

$\mathrm{D}_{t}=\frac{\left(\frac{\eta_{t}}{1-\eta_{t}}\right) \frac{\widetilde{w}_{t}}{y_{t}}}{\frac{\widetilde{w}_{t}}{y_{t}}+\phi_{W}\left(\frac{W_{t}}{z \pi_{t-1}^{\varrho} \pi^{1-\varrho} W_{t-1}}-1\right)\left(\frac{W_{t}}{z \pi_{t-1}^{\varrho} \pi^{1-\varrho} W_{t-1}}\right)-\beta \chi \phi_{W} E_{t}\left[\frac{\lambda_{t+1}}{\lambda_{t}}\left(\frac{W_{t+1}}{z \pi_{t}^{\varrho} \pi^{1-\varrho} W_{t}}-1\right)\left(\frac{W_{t+1}}{z \pi_{t}^{\varrho} \pi^{1-\varrho} W_{t}}\right) \frac{y_{t+1}}{y_{t}}\right]}$

28. $\eta_{t}$

$$
\ln \eta_{t}=\left(1-\rho_{\eta}\right) \ln \eta+\rho_{\eta} \ln \eta_{t-1}+\varepsilon_{\eta t}
$$

29. $r_{t}^{B}$

$$
\ln \left(\frac{r_{t}^{B}}{r^{B}}\right)=\rho_{r} \ln \left(\frac{r_{t-1}^{B}}{r^{B}}\right)+\left(1-\rho_{r}\right)\left[\rho_{\pi} \ln \left(\frac{\pi_{t}}{\pi}\right)+\rho_{y} \ln \left(\frac{y_{t}}{y_{t-1}} z_{t}\right)\right]+\ln \epsilon_{m p t}
$$


30. $\epsilon_{r t}$

$$
\ln \epsilon_{m p t}=\rho_{m p} \ln \epsilon_{m p t-1}+\varepsilon_{m p t}
$$

31. $g_{t}=G_{t} / A_{t}$

$$
g_{t}=\left(1-\frac{1}{\epsilon_{g t}}\right) y_{t}
$$

32. $\epsilon_{g t}$

$$
\ln \epsilon_{g t}=\left(1-\rho_{g}\right) \ln \epsilon_{g}+\rho_{g} \ln \epsilon_{g t-1}+\varepsilon_{g t}
$$

33. $g y_{t}=Y_{t} / Y_{t-1}$

$$
g y_{t}=\frac{y_{t}}{y_{t-1}} z_{t}
$$

34. $g c_{t}=C_{t} / C_{t-1}$

$$
g c_{t}=\left(\frac{c_{t}}{c_{t-1}}\right) z_{t}
$$

35. $g i_{t}=I_{t} / I_{t-1}$

$$
g i_{t}=\left(\frac{i_{t}}{i_{t-1}}\right) z_{t}
$$

36. $g w_{t}=\widetilde{W}_{t} / \widetilde{W}_{t-1}$

$$
g w_{t}=\left(\frac{\widetilde{w}_{t}}{\widetilde{w}_{t-1}}\right) z_{t}
$$

The steady state of the transformed stationary economy

In the absence of shocks, the economy converges to a steady-state growth path in which all stationary variables are constant: for all $t, y_{t}=y, k_{t}=k, \bar{k}_{t}=\bar{k}, u_{t}=u=1, \lambda_{t}=\lambda, v_{t}=v$, $\xi_{t}=\xi, c_{t}=c, \widetilde{r}_{t}^{K}=\widetilde{r}^{K}, i_{t}=i, g_{t}=g, N_{t}=N, S_{t}=S, U_{t}=U, V_{t}=V, x_{t}=x, q_{t}=q, s_{t}=s$, $\mathrm{D}_{t}=\mathrm{D}, \widetilde{w}_{t}=\widetilde{w}, \widetilde{\mathbf{b}}=\widetilde{\mathbf{b}}, r_{t}^{B}=r^{B}, \pi_{t}=\pi, \mu_{t}=\mu=1, \epsilon_{b t}=\epsilon_{b}=1, z_{t}=z, \theta_{t}=\theta, \eta_{t}=\eta$, $\epsilon_{g t}=\epsilon_{g}, \epsilon_{r t}=\epsilon_{r}, g_{y t}=g_{c t}=g_{I t}=g_{A t}=z, c y r_{t}=c y r, i y r_{t}=i y r, \Theta_{t}=\Theta$. Notice that the steady-state values $\mu, u$ and $\epsilon_{b}$ are normalized to 1 . 
1. $\mu_{t}$

$$
\ln \mu=0 \Rightarrow \mu=1
$$

2. $\epsilon_{b t}$

$$
\ln \epsilon_{b}=0 \Rightarrow \epsilon_{b}=1
$$

3. $u_{t}$

$$
u=1
$$

4. $z_{t}$

$z$ : calibrated at sample mean of gross quarterly growth rate of per-capita real output

5. $g y_{t}$

$$
g y=z
$$

6. $g c_{t}$

$$
g c=z
$$

7. $g i_{t}$

$$
g i=z
$$

8. $g w_{t}$

$$
g w=z
$$

9. $g_{t}$

$$
\frac{g}{y}=\left(1-\frac{1}{\epsilon_{g}}\right):=0.20(\text { calibrated })
$$

10. $\epsilon_{g t}$

$$
\left(\frac{1}{\epsilon_{g}}-\frac{\phi_{N}}{2} x^{2}\right) y=c+i
$$


11. $k_{t}$

$$
z k=\bar{k}
$$

12. $\bar{k}_{t}$

$$
(z-1+\delta) \bar{k}=z i
$$

13. $\lambda_{t}$

$$
\beta=\frac{\pi z}{r^{B}}
$$

14. $c_{t}$

$$
\lambda c=\frac{z-\beta h}{z-h}
$$

15. $\widetilde{r}_{t}^{K}$

$$
\phi_{u 1}=\widetilde{r}^{K}
$$

16. $i_{t}$

$$
1=v
$$

17. $v_{t}$

$$
\frac{z}{\beta}=1-\delta+\widetilde{r}^{K}
$$

18. $N_{t}$

$$
\rho N=q V \quad \text { where } \rho \equiv 1-\chi
$$

19. $S_{t}$

$$
S=1-\chi N
$$

20. $U_{t}$

$U$ : calibrated at sample mean of unemployment rate 
21. $V o S_{t}$

$$
V o S=\frac{V}{S}
$$

22. $\Theta_{t}=\frac{V_{t}}{U_{t}}$

$$
\Theta=\frac{V}{U}
$$

23. $q_{t}$

$$
q=\zeta\left(\frac{S}{V}\right)^{\sigma}:=0.7 \text { (calibrated) }
$$

24. $s_{t}$

$$
s=\zeta\left(\frac{V}{S}\right)^{1-\sigma}
$$

25. $y_{t}$

$$
y=k^{\alpha} N^{1-\alpha}
$$

26. $\xi_{t}$

$$
\widetilde{r}^{K}=\alpha \frac{y}{k} \xi
$$

27. $V_{t}$

$$
x=\frac{q V}{N}
$$

28. $x_{t}$

$$
(1-x-\beta \chi) \phi_{N} x=\xi(1-\alpha)-\frac{\widetilde{w} N}{y}
$$

29. $\theta_{t}$

$$
\xi=\frac{\theta-1}{\theta}
$$

30. $\pi_{t}$

$\pi$ : calibrated at sample mean of gross quarterly growth rate GDP deflator 
31. $\widetilde{\mathbf{b}}_{t}$

$$
\widetilde{\mathbf{b}}=\tau \widetilde{w}
$$

32. $\widetilde{w}_{t}$

$$
\begin{aligned}
{\left[\frac{1-(1-\eta) \tau}{\eta}\right] \frac{\widetilde{w} N}{y} } & =\xi(1-\alpha)+\phi_{N} x^{2}+\beta \chi \phi_{N} x s \\
\frac{1-(1-\eta) \tau}{\eta} & =\frac{\left[\xi(1-\alpha)+\phi_{N} x^{2}+\beta \chi \phi_{N} x s\right]}{\frac{\widetilde{w} N}{y}}
\end{aligned}
$$

33. $\mathrm{D}_{t}$

$$
\mathrm{b}=\frac{\eta}{1-\eta}
$$

34. $\eta_{t}$

$$
\eta=?
$$

35. $\epsilon_{r t}$

$$
\epsilon_{m p}=1
$$

36. $r_{t}^{B}$

$r^{B}$ : calibrated at sample mean of gross quarterly nominal rate of interest

37. $\widetilde{r}_{t}^{B}$

$$
\widetilde{r}^{B}=\frac{r^{B}}{\pi}
$$

38. $\pi_{t}^{w}$

$$
\pi^{w}=z \pi
$$

\section{The log-linearized model}

1. $y_{t}$

$$
\left(\frac{1}{\epsilon_{g}}-\frac{\phi_{N}}{2} x^{2}\right) \widehat{y}_{t}=\frac{c}{y} \widehat{c}_{t}+\frac{i}{y} \widehat{i}_{t}+\left(\phi_{u 1} \frac{k}{y}\right) \widehat{u}_{t}+\left(\phi_{N} x^{2}\right) \widehat{x}_{t}+\frac{1}{\epsilon_{g}} \widehat{\epsilon}_{g t}
$$


2. $k_{t}$

$$
\widehat{z}_{t}+\widehat{k}_{t}=\widehat{u}_{t}+\widehat{\bar{k}}_{t-1}
$$

3. $\bar{k}_{t}$

$$
z \widehat{\bar{k}}_{t}=(1-\delta)\left(\widehat{\bar{k}}_{t-1}-\widehat{z}_{t}\right)+(z-1+\delta)\left(\widehat{\mu}_{t}+\widehat{i}_{t}\right)
$$

4. $\lambda_{t}$

$$
\widehat{\lambda}_{t}=\widehat{\epsilon}_{b t}+\widehat{r}_{t}^{B}+\widehat{\lambda}_{t+1}-\widehat{\pi}_{t+1}-\widehat{z}_{t+1}
$$

5. $c_{t}$

$$
\begin{aligned}
\widehat{\lambda}_{t}= & \frac{\beta h z}{(z-\beta h)(z-h)} \widehat{c}_{t+1}-\frac{z^{2}+\beta h^{2}}{(z-\beta h)(z-h)} \widehat{c}_{t}+\frac{h z}{(z-\beta h)(z-h)} \widehat{c}_{t-1} \\
& +\frac{\beta h z}{(z-\beta h)(z-h)} \widehat{z}_{t+1}-\frac{h z}{(z-\beta h)(z-h)} \widehat{z}_{t}
\end{aligned}
$$

6. $\widetilde{r}_{t}^{K}$

$$
\widehat{\widetilde{r}}_{t}^{K}=\left(\frac{\phi_{u 2}}{\phi_{u 1}}\right) \widehat{u}_{t}
$$

7. $i_{t}$

$$
\widehat{v}_{t}=\left(\phi_{I} z^{2}\right)\left(\widehat{i}_{t}-\widehat{i}_{t-1}+\widehat{z}_{t}\right)-\widehat{\mu}_{t}-\left(\beta \phi_{I} z^{2}\right)\left(\widehat{i}_{t+1}-\widehat{i}_{t}+\widehat{z}_{t+1}\right)
$$

8. $v_{t}$

$$
\widehat{v}_{t}=\widehat{\lambda}_{t+1}-\widehat{\lambda}_{t}-\widehat{z}_{t+1}+\left[(1-\delta) \beta z^{-1}\right] \widehat{v}_{t+1}+\left(\beta z^{-1} \widetilde{r}^{K}\right) \widehat{\widetilde{r}}_{t+1}^{K}
$$

9. $u_{t}$

$$
\widehat{y}_{t}=\alpha \widehat{k}_{t}+(1-\alpha) \widehat{N}_{t}
$$

10. $\xi_{t}$

$$
\widehat{\widetilde{r}}_{t}^{K}=\widehat{\xi}_{t}+\widehat{y}_{t}-\widehat{k}_{t}
$$

11. $N_{t}$

$$
\widehat{N}_{t}=\chi \widehat{N}_{t-1}+x\left(\widehat{q}_{t}+\widehat{V}_{t}\right)
$$


12. $S_{t}$

$$
\widehat{S}_{t}=-\left(\frac{\chi N}{S}\right) \widehat{N}_{t-1}
$$

13. $U_{t}$

$$
\widehat{U}_{t}=-\frac{N}{U} \widehat{N}_{t}
$$

14. $V o S_{t}$

$$
\widehat{V O S}_{t}=\widehat{V}_{t}-\widehat{S}_{t}
$$

15. $\Theta_{t}$

$$
\widehat{\Theta}_{t}=\widehat{V}_{t}-\widehat{U}_{t}
$$

16. $q_{t}$

$$
\widehat{q}_{t}=-\sigma \widehat{V O S}_{t}
$$

17. $s_{t}$

$$
\widehat{s}_{t}=(1-\sigma) \widehat{V o S}_{t}
$$

18. $V_{t}$

$$
\widehat{x}_{t} \equiv \widehat{q}_{t}+\widehat{V}_{t}-\widehat{N}_{t}
$$

19. $x_{t}$

$$
\begin{aligned}
\widehat{x}_{t}= & {\left[\frac{(1-\alpha) \xi}{\phi_{N} x(1-2 x)}\right] \widehat{\xi}_{t}-\left[\frac{1}{\phi_{N} x(1-2 x)} \frac{\widetilde{w} N}{y}\right]\left(\widehat{\widetilde{w}}_{t}+\widehat{N}_{t}-\widehat{y}_{t}\right) } \\
& +\left[\frac{\beta \chi}{1-2 x}\right]\left(\widehat{\lambda}_{t+1}-\widehat{\lambda}_{t}+\widehat{N}_{t}-\widehat{N}_{t+1}+\widehat{y}_{t+1}-\widehat{y}_{t}+\widehat{x}_{t+1}\right)
\end{aligned}
$$

20. $\pi_{t}$

$$
\widehat{\pi}_{t}=\left(\frac{\varsigma}{1+\beta \varsigma}\right) \widehat{\pi}_{t-1}+\left(\frac{\beta}{1+\beta \varsigma}\right) \widehat{\pi}_{t+1}+\left(\frac{1}{1+\beta \varsigma}\right)\left(\frac{\theta-1}{\phi_{P}}\right) \widehat{\xi}_{t}-\left(\frac{1}{1+\beta \varsigma}\right)\left(\frac{1}{\phi_{P}}\right) \widehat{\theta}_{t}
$$

21. $\widetilde{\mathbf{b}}_{t}=\widetilde{\mathbf{b}}=\tau \widetilde{w}$

$$
\widehat{\widetilde{\mathbf{b}}}_{t}=0
$$


22. $\widetilde{w}_{t}$

$$
\begin{aligned}
\left(\frac{1}{\eta} \frac{\widetilde{w} N}{y}\right) \widehat{\widetilde{w}}_{t}= & {[(1-\alpha) \xi] \widehat{\xi}_{t}+\left[(1-\alpha) \xi+\phi_{N} x^{2}\right]\left(\widehat{y}_{t}-\widehat{N}_{t}\right)+\left(2 \phi_{N} x^{2}\right) \widehat{x}_{t} } \\
& -\left[\frac{\widetilde{w} N}{y}-(1-\alpha) \xi-\phi_{N} x^{2}-\beta \chi \phi_{N} x\right] \widehat{\mathrm{D}}_{t} \\
& +\left(\beta \chi \phi_{N} x\right)\left[s\left(\widehat{\lambda}_{t+1}-\widehat{\lambda}_{t}+\widehat{y}_{t+1}-\widehat{N}_{t+1}+\widehat{x}_{t+1}+\widehat{s}_{t+1}\right)-(1-s) \widehat{\mathrm{D}}_{t+1}\right]
\end{aligned}
$$

23. $\mathrm{D}_{t}$

$\widehat{\mathrm{D}}_{t}=\left(\frac{1}{1-\eta}\right) \widehat{\eta}_{t}+\phi_{W}\left(\frac{y}{\widetilde{w}}\right)\left[\beta \chi\left(\widehat{z}_{t+1}+\widehat{\pi}_{t+1}+\widehat{\widetilde{w}}_{t+1}-\widehat{\widetilde{w}}_{t}-\varrho \widehat{\pi}_{t}\right)-\left(\widehat{z}_{t}+\widehat{\pi}_{t}+\widehat{\widetilde{w}}_{t}-\widehat{\widetilde{w}}_{t-1}-\varrho \widehat{\pi}_{t-1}\right)\right]$

24. $r_{t}^{B}$

$$
\widehat{r}_{t}^{B}=\rho_{r} \widehat{r}_{t-1}^{B}+\left(1-\rho_{r}\right)\left[\rho_{\pi} \widehat{\pi}_{t}+\rho_{y}\left(\widehat{y}_{t}-\widehat{y}_{t-1}+\widehat{z}_{t}\right)\right]+\widehat{\epsilon}_{m p t}
$$

25. $g_{t}=G_{t} / A_{t}$

$$
\widehat{g}_{t}=\widehat{y}_{t}+\left(\frac{y}{g}-1\right) \widehat{\epsilon}_{g t}
$$

26. $g y_{t}=Y_{t} / Y_{t-1}$

$$
\widehat{g y}_{t}=\widehat{y}_{t}-\widehat{y}_{t-1}+\widehat{z}_{t}
$$

27. $g c_{t}=C_{t} / C_{t-1}$

$$
\widehat{g c}_{t}=\widehat{c}_{t}-\widehat{c}_{t-1}+\widehat{z}_{t}
$$

28. $g i_{t}=I_{t} / I_{t-1}$

$$
\widehat{g i}_{t}=\widehat{i}_{t}-\widehat{i}_{t-1}+\widehat{z}_{t}
$$

29. $g w_{t}=\widetilde{W}_{t} / \widetilde{W}_{t-1}$

$$
\widehat{g w}_{t}=\widehat{\widetilde{w}}_{t}-\widehat{\widetilde{w}}_{t-1}+\widehat{z}_{t}
$$

30. $\mu_{t}$

$$
\widehat{\mu}_{t}=\rho_{\mu} \widehat{\mu}_{t-1}+\varepsilon_{\mu t}
$$


31. $\epsilon_{b t}$

$$
\widehat{\epsilon}_{b t}=\rho_{b} \widehat{\epsilon}_{b t-1}+\varepsilon_{b t}
$$

32. $z_{t}$

$$
\widehat{z}_{t}=\rho_{z} \widehat{z}_{t-1}+\varepsilon_{z t}
$$

33. $\theta_{t}$

$$
\widehat{\theta}_{t}=\rho_{\theta} \widehat{\theta}_{t-1}+\varepsilon_{\theta t}
$$

34. $\eta_{t}$

$$
\widehat{\eta}_{t}=\rho_{\eta} \widehat{\eta}_{t-1}+\varepsilon_{\eta t}
$$

35. $\epsilon_{g t}$

$$
\widehat{\epsilon}_{g t}=\rho_{g} \widehat{\epsilon}_{g t-1}+\varepsilon_{g t}
$$

36. $\epsilon_{r t}$

$$
\widehat{\epsilon}_{m p t}=\rho_{m p} \widehat{\epsilon}_{m p t-1}+\varepsilon_{m p t}
$$

\section{Rescaling two shocks prior to estimation}

Two disturbances are normalized prior to estimation: the price-markup shock $\widehat{\theta}_{t}$ and the wage-markup shock $\widehat{\eta}_{t}$. The 2 rescaled disturbances which enter into the estimated model are

$$
\begin{aligned}
\widehat{\theta}_{t}^{*} & =\left[\frac{1}{(1+\beta \varsigma) \phi_{P}}\right] \widehat{\theta}_{t}, \\
\widehat{\theta}_{t}^{*} & =\rho_{\theta^{*}} \widehat{\theta}_{t-1}^{*}-\varepsilon_{\theta^{*} t}, \\
\rho_{\theta^{*}} & =\rho_{\theta}, \\
\varepsilon_{\theta^{*} t} & \sim i \cdot i \cdot d \cdot N\left(0, \sigma_{\theta^{*}}^{2}\right), \\
\sigma_{\theta^{*}} & =\left[\frac{1}{(1+\beta \varsigma) \phi_{P}}\right] \sigma_{\theta},
\end{aligned}
$$




$$
\begin{aligned}
\widehat{\eta}_{t}^{*} & =\left(\frac{1}{1-\eta}\right) \widehat{\eta}_{t}, \\
\widehat{\eta}_{t}^{*} & =\rho_{\eta^{*}} \widehat{\eta}_{t-1}^{*}+\varepsilon_{\eta^{*} t}, \\
\rho_{\eta^{*}} & =\rho_{\eta}, \\
\varepsilon_{\eta^{*} t} & \sim i . i . d . N\left(0, \sigma_{\eta^{*}}^{2}\right), \\
\sigma_{\eta^{*}} & =\left(\frac{1}{1-\eta}\right) \sigma_{\eta} .
\end{aligned}
$$

The two rescaled disturbances enter with a unit coefficient in the following two equations respectively:

1. $\pi_{t}$

$$
0=\widehat{\pi}_{t}-\left(\frac{\varsigma}{1+\beta \varsigma}\right) \widehat{\pi}_{t-1}-\left(\frac{\beta}{1+\beta \varsigma}\right) \widehat{\pi}_{t+1}-\left(\frac{1}{1+\beta \varsigma}\right)\left(\frac{\theta-1}{\phi_{P}}\right) \widehat{\xi}_{t}+\widehat{\theta}_{t}^{*}
$$

2. $\mathrm{D}_{t}$

$$
\begin{aligned}
0= & \widehat{\mathrm{D}}_{t}-\widehat{\eta}_{t}^{*}-\left(\beta \chi \phi_{W} \frac{y}{\widetilde{w}}\right) \widehat{z}_{t+1}-\left(\beta \chi \phi_{W} \frac{y}{\widetilde{w}}\right) \widehat{\pi}_{t+1}-\left(\beta \chi \phi_{W} \frac{y}{\widetilde{w}}\right) \widehat{\widetilde{w}}_{t+1}+\left[\left(\phi_{W} \frac{y}{\widetilde{w}}\right)(1+\beta \chi)\right] \widehat{\widetilde{w}}_{t} \\
& +\left[\left(\phi_{W} \frac{y}{\widetilde{w}}\right)(1+\beta \chi \varrho)\right] \widehat{\pi}_{t}+\left(\phi_{W} \frac{y}{\widetilde{w}}\right) \widehat{z}_{t}-\left(\phi_{W} \frac{y}{\widetilde{w}}\right) \widehat{\widetilde{w}}_{t-1}-\left(\phi_{W} \frac{y}{\widetilde{w}}\right) \varrho \widehat{\pi}_{t-1} .
\end{aligned}
$$




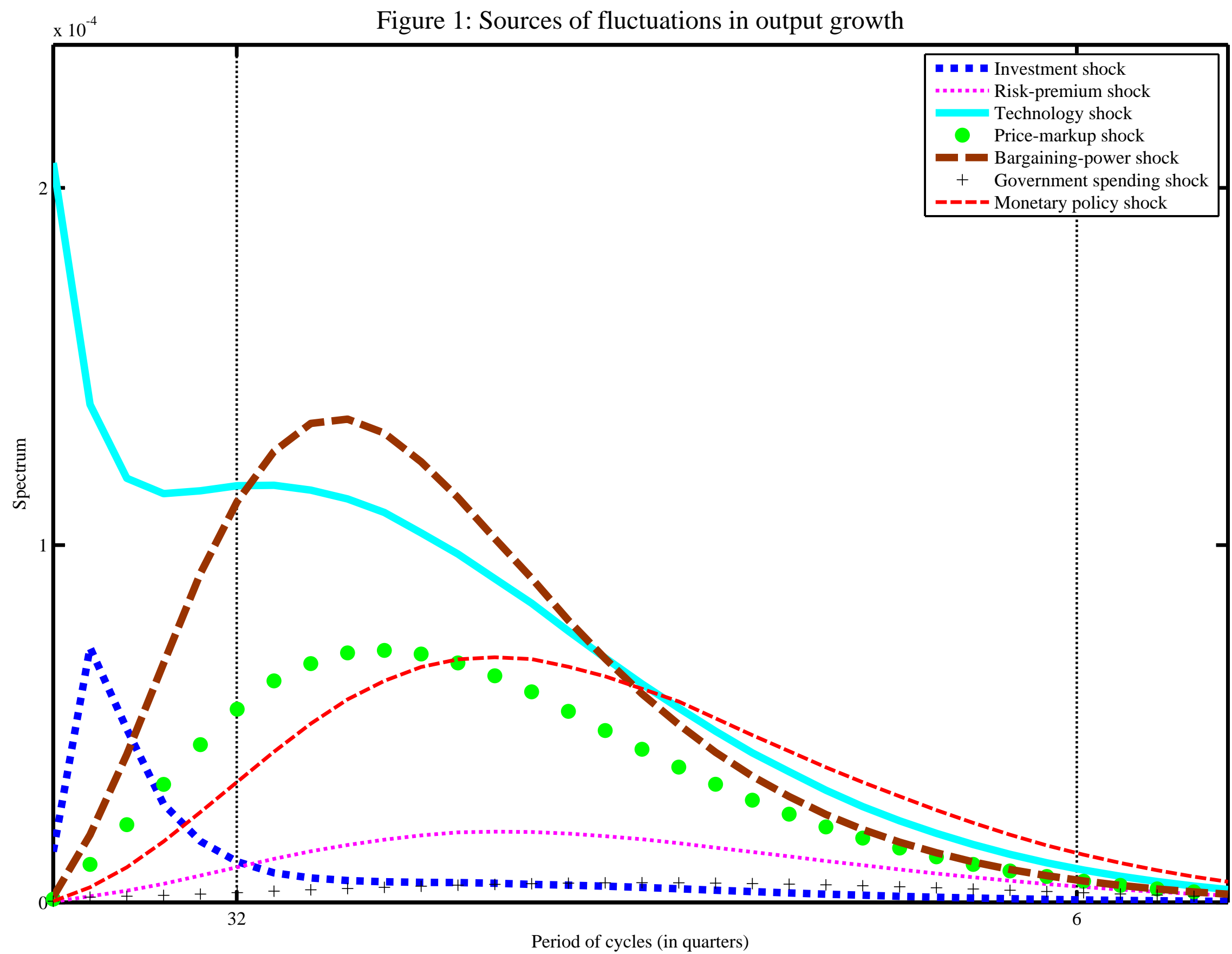


Figure 2: The natural rate of unemployment

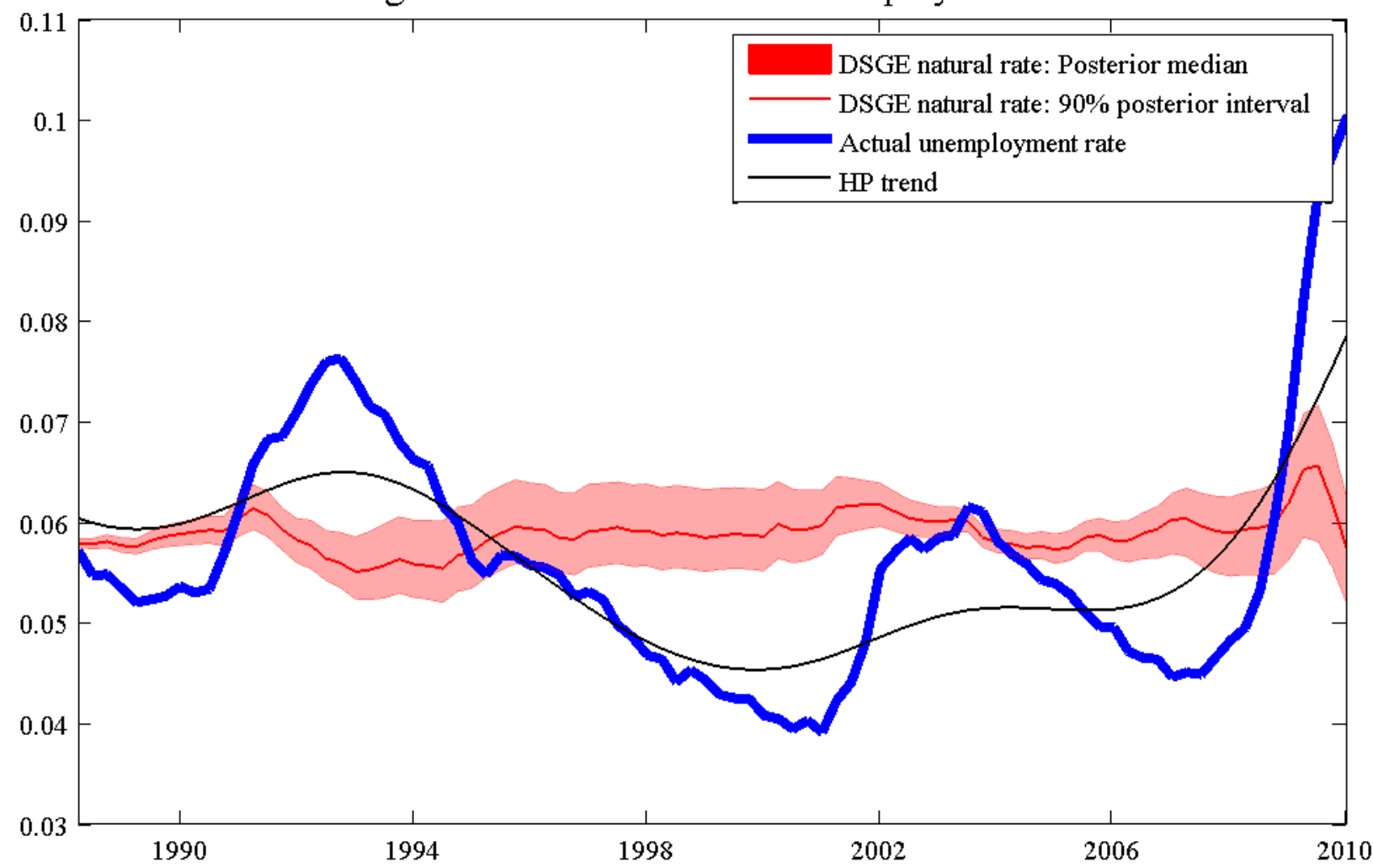

Figure 3: The unemployment gap

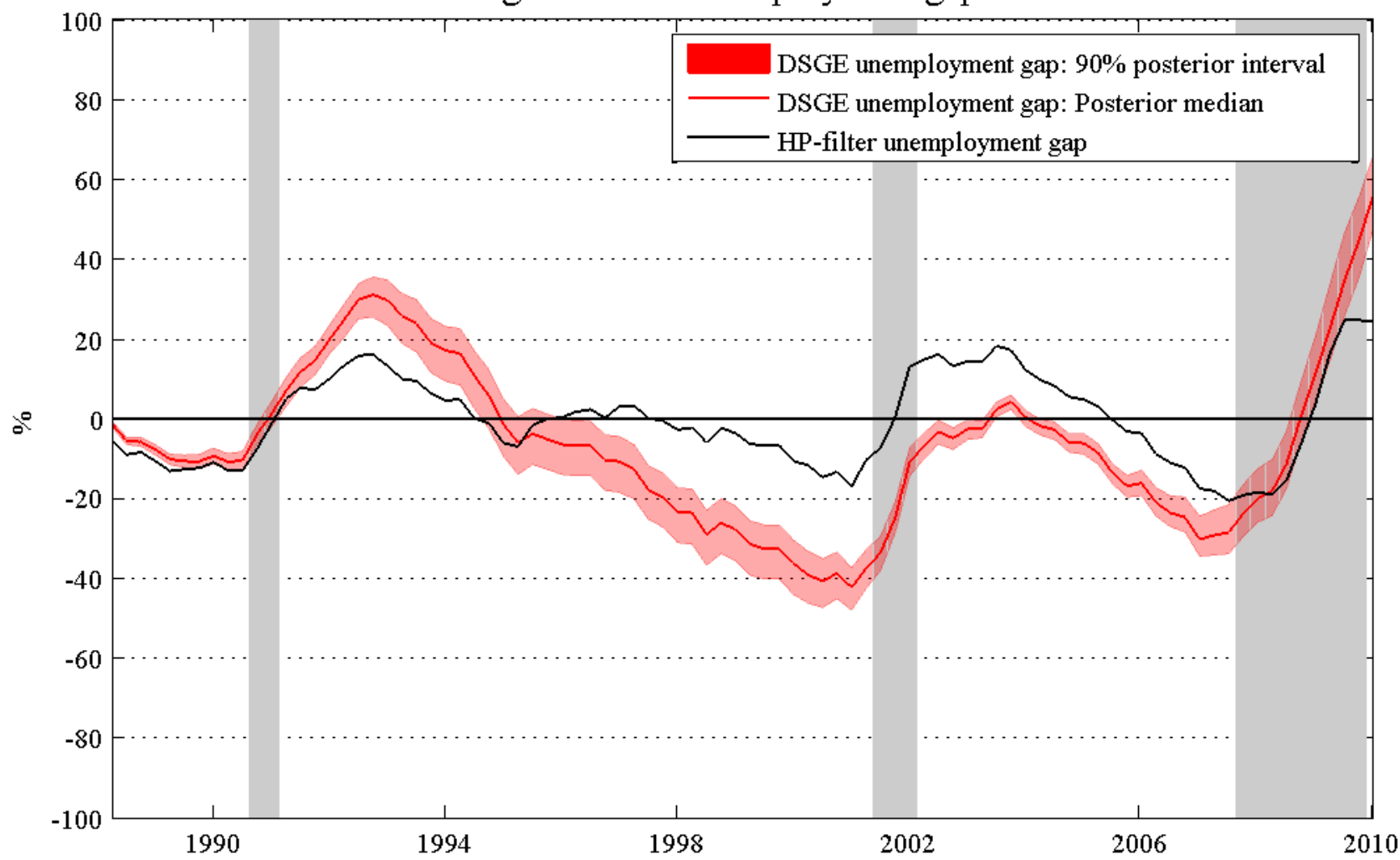


Figure 4: Historical decompositions of the unemployment gap

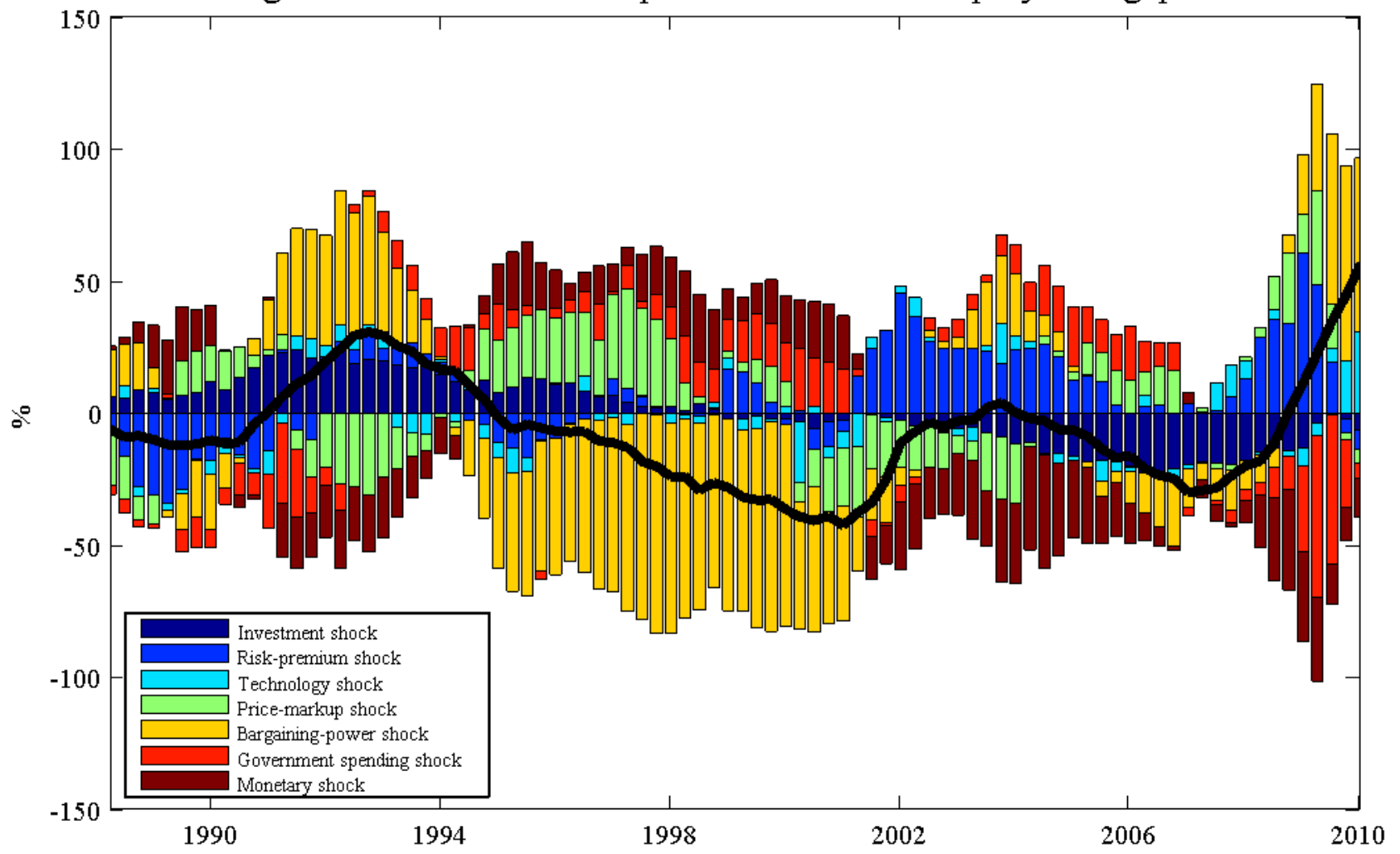

Figure 5: Historical decompositions of inflation

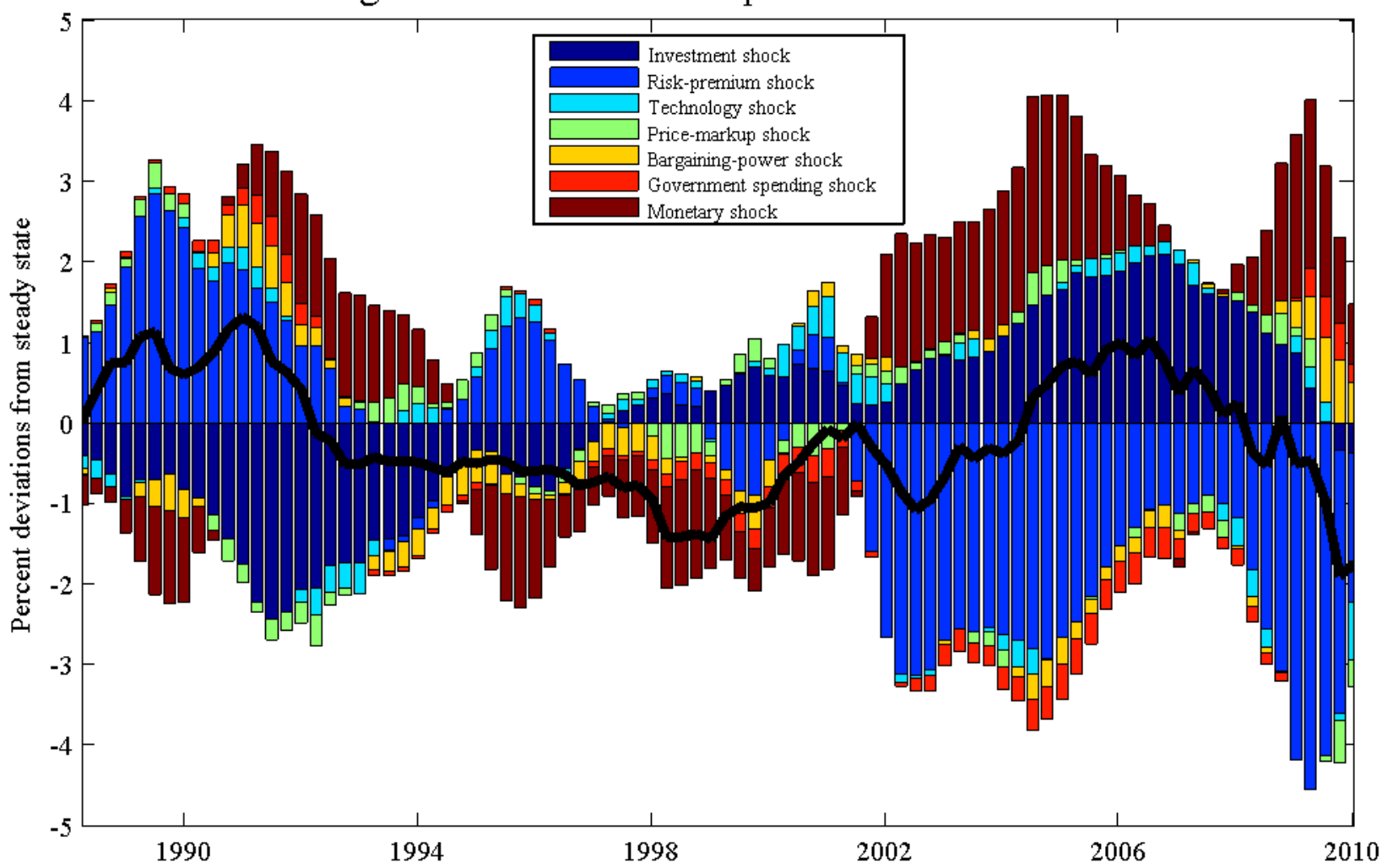


Figure 6: Monetary policy shocks

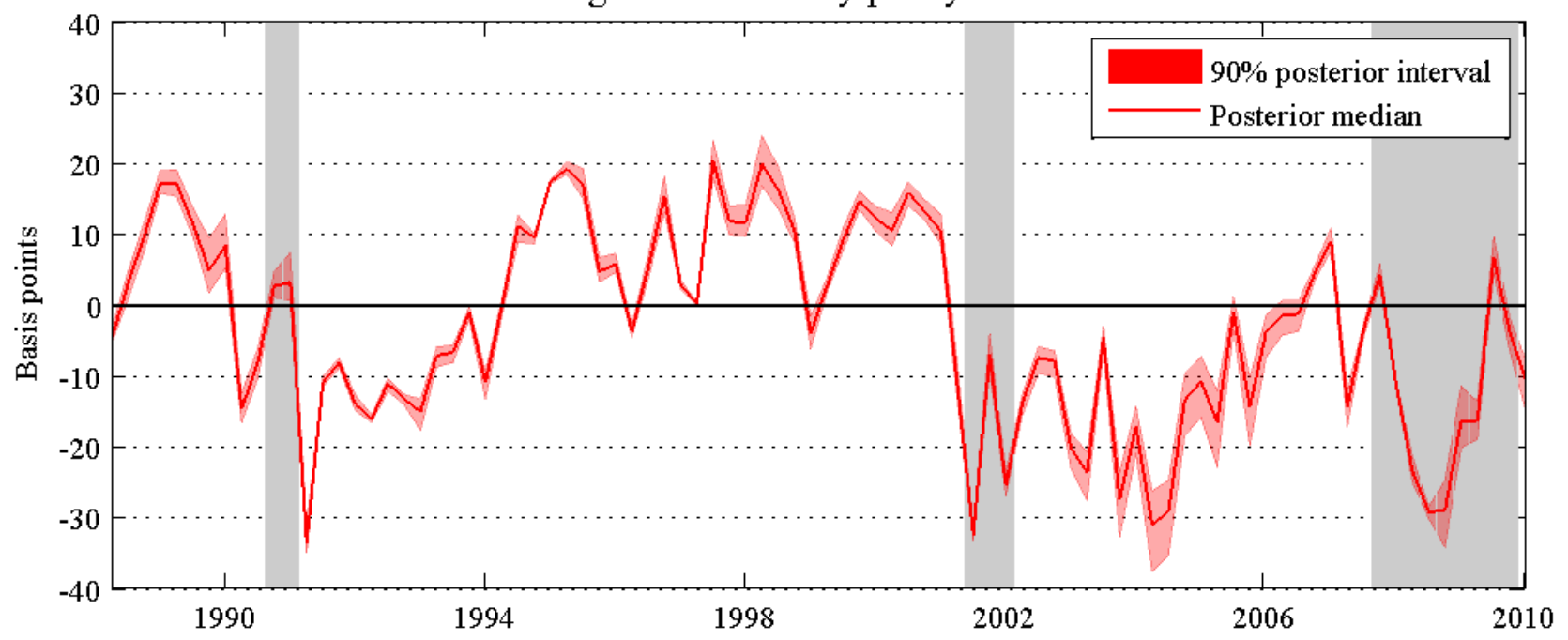

Figure 7: Inflation and counterfactual with no monetary policy shocks

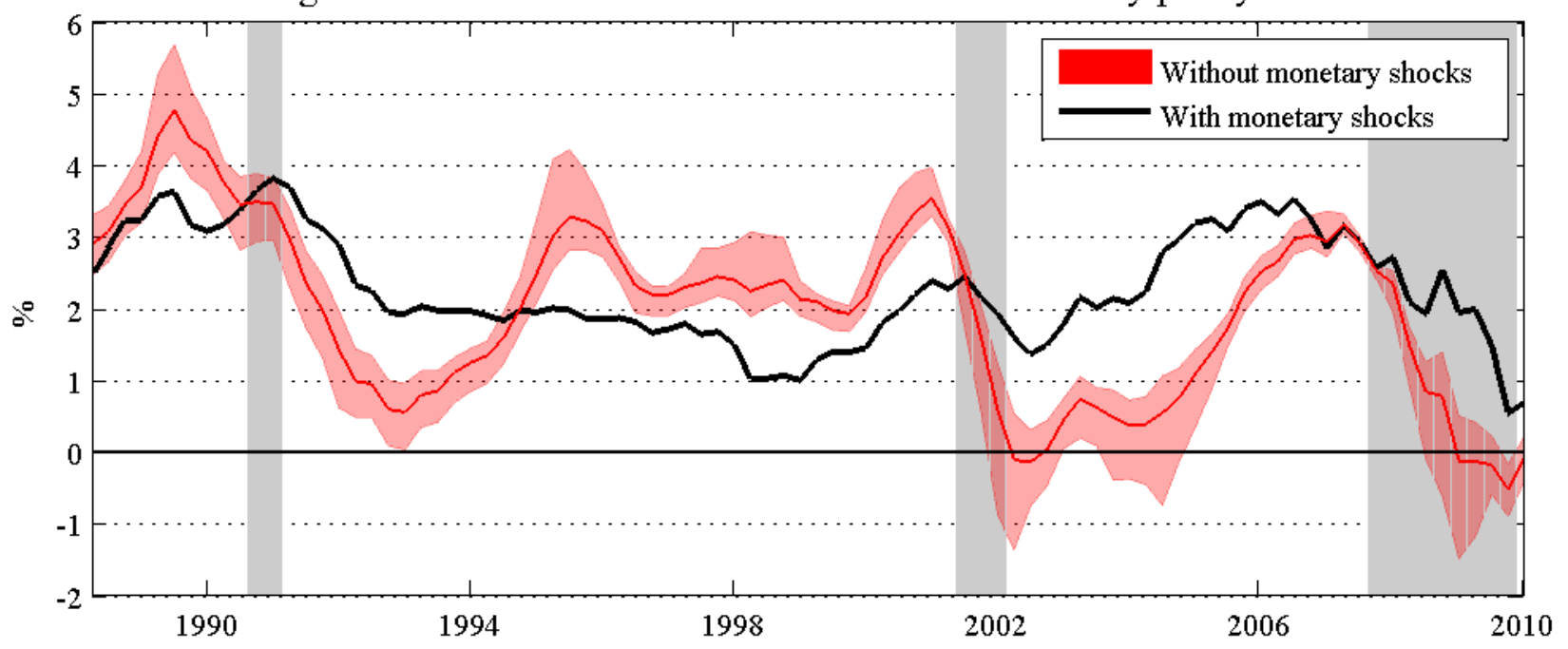

Figure 8: Unemployment gap and counterfactual with no monetary policy shocks

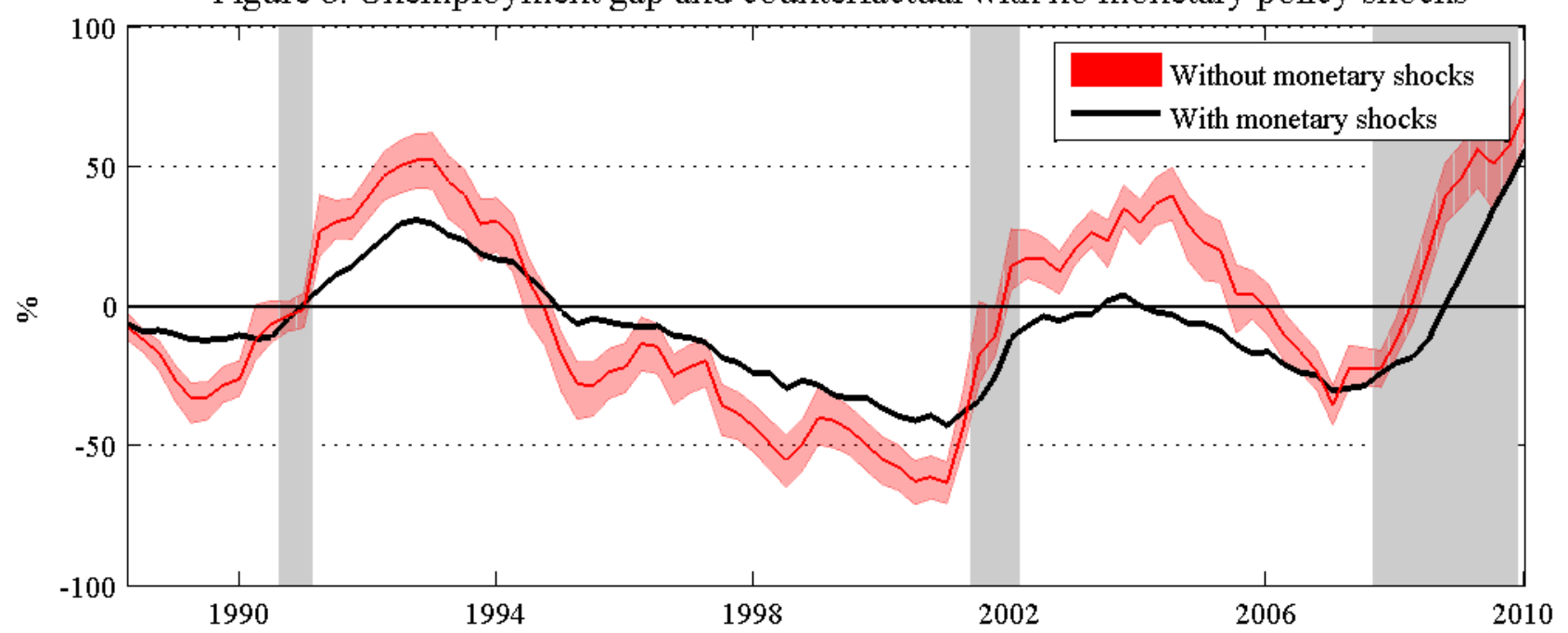

